Santis, W., Castellanos, P., \& Campos, E. (2020). Memory effect of the Southern Atlantic subtropical dipole. Journal of Climate, 33(17), 76797696. https://doi.org/10.1175/JCLI-D-19-0745.1

(C) Copyright 2020 American Meteorological Society (AMS). Permission to use figures, tables, and brief excerpts from this work in scientific and educational works is hereby granted provided that the source is acknowledged. Any use of material in this work that is determined to be "fair use" under Section 107 of the U.S. Copyright Act or that satisfies the conditions specified in Section 108 of the U.S. Copyright Act (17 USC \$108) does not require the AMS’s permission. Republication, systematic reproduction, posting in electronic form, such as on a website or in a searchable database, or other uses of this material, except as exempted by the above statement, requires written permission or a license from the AMS. All AMS journals and monograph publications are registered with the Copyright Clearance Center (http:// www.copyright.com). Questions about permission to use materials for which AMS holds the copyright can also be directed to permissions@ametsoc.org. Additional details are provided in the AMS Copyright Policy statement, available on the AMS website (http:// www.ametsoc.org/CopyrightInformation). 


\title{
Memory Effect of the Southern Atlantic Subtropical Dipole $\mathscr{O}$
}

\author{
WLADEMIR SANTIS \\ Instituto Oceanográfico da Universidade de São Paulo, São Paulo, Brazil \\ PaOla CASTEllanos \\ Marine and Environmental Sciences Centre, Faculdade de Ciências da Universidade de Lisboa, Lisbon, Portugal \\ EDMO CAMPOS \\ Instituto Oceanográfico da Universidade de São Paulo, São Paulo, Brazil College of Arts and Sciences of the American \\ University of Sharjah, Sharjah, United Arab Emirates
}

(Manuscript received 4 October 2019, in final form 3 June 2020)

\begin{abstract}
The South Atlantic subtropical dipole is the dominant mode of coupled variability in the South Atlantic, connecting sea level pressure and sea surface temperature. Previous studies have shown its great relevance to the climate conditions over South America and West Africa. We have used several numerical experiments with the Hybrid Coordinate Ocean Model to investigate the effects that an austral winter-spring dipole asserts on the South Atlantic. We explore the interaction between SST anomalies and the formation of the fossilized mixing region, which preserve temperature anomalies underneath the summer mixed layer, until they feed back to SST after the next autumn. It was found that, through this process, there is a memory effect that restores temperature anomalies from an austral winter-spring dipole back to the austral winter of the following year. The dominant mechanisms are the contribution from entrainment and surface net heat flux (NHF). Entrainment is mostly controlled by vertical temperature gradient anomalies, while surface NHF is controlled by interactions of climatological ocean heat loss and anomalies of mixed layer thickness. Our results suggest that the combined effect of entrainment and surface NHF is different in the southwest and northeast dipole regions, leading to differences in both intensity and timing of SST anomalies. Turbulent and nonlinear processes are most important to reduce entrainment in the southwest dipole region and to increase the memory effect asymmetry.
\end{abstract}

\section{Introduction}

The South Atlantic has rich and complex modes of variability. In the subtropics, a southwest-northeastoriented dipole with opposed SST anomalies has been described (Venegas et al. 1997; Sterl and Hazeleger 2003; Haarsma et al. 2005; Morioka et al. 2011; Nnamchi et al. 2017). The dipole is usually referred to as the South Atlantic subtropical dipole (SASD), and is the dominant mode of coupled variability in the South Atlantic, connecting sea level pressure (SLP) and sea surface

\footnotetext{
Supplemental information related to this paper is available at the Journals Online website: https://doi.org/10.1175/JCLI-D-190745.s1.

Corresponding author: Wlademir Santis, wlademir.santis@usp.br
}

temperature (SST) (Venegas et al. 1997; Sterl and Hazeleger 2003; Morioka et al. 2011; Haarsma et al. 2005). There is, however, a different variant of the South Atlantic dipole defined in the literature: the South Atlantic Ocean dipole (SAOD; Nnamchi et al. 2011; Nnamchi and Li 2011; Nnamchi et al. 2016, 2017). These distinct definitions arise from differences in the seasonal position of the St. Helena subtropical anticyclone, which produces a seasonality in the dipole as well (Nnamchi et al. 2016). Thus, studies that have focused their attention on austral summer have usually observed and defined the SASD, while those interested in austral winter have usually observed and defined the SAOD. In other words, the SAOD best expresses austral winter dipole events, which covers a broader area and peaks in JJA, whereas the SASD is stronger during austral summer and more restricted to higher latitudes (Nnamchi 
et al. 2017). Nevertheless, both are the same mode of variability, originating from fluctuations in the subtropical anticyclone (Nnamchi et al. 2016). After that been said, hereinafter we use the usual SASD definition, and the SAOD is referred to as austral winter SASD.

The life cycle of an austral summer SASD is described in Morioka et al. (2011, hereafter MK11). According to the authors, during the growth phase, SASD events start with anomalies in the strength and position of the subtropical high (and its associated surface wind), leading to a dipole-like anomaly of latent heat flux in the ocean, which affects the mixed layer thickness. Following this, the warming of the thinner (thicker) mixed layer by the climatological shortwave radiation is enhanced (suppressed). In early autumn, the decay phase is triggered by entrainment, which is enhanced (suppressed) on the positive (negative) SST pole. According to the authors, an anomalous contribution from the entrainment is due to temperature anomalies in the mixed layer that affect the vertical temperature gradient, and not to the underlying temperature. In addition, climatological latent heat flux and mixed layer thickness anomalies also contribute to damp the SST anomaly. The life cycle of an austral winter SASD is investigated in Nnamchi et al. (2016), suggesting that net heat flux anomalies largely drive the dipole, while ocean dynamics are of secondary importance.

The mechanism initiating a SASD event is attributed to intrinsic atmospheric variability. There are many attempts to assess whether external forcings might trigger its atmospheric component. Rodrigues et al. (2015) have performed numerical experiments with a coupled model and suggested that SASD events are correlated with specific central Pacific ENSO events (Ashok et al. 2007; Trenberth 1997), while such correlation is absent with eastern Pacific ENSO. The authors have suggested that central Pacific ENSO produces the right Pacific-South America wave train (Mo and Paegle 2001) that affects both strength and position of the South Atlantic subtropical high, triggering SASD events. Morioka et al. (2014), on the other hand, have studied the relationship between tropical SST variability and SASD events, demonstrating that, when tropical SST variability is suppressed, the Antarctic Oscillation (AAO; Thompson et al. 2000) becomes dominant, producing stationary Rossby waves that affect sea level pressure and initiate the SASD. Hermes and Reason (2005) and Fauchereau et al. (2003) have suggested that, although there are independent dipole events in each southern basin, there are also synchronous events where a coherent pattern in the Southern Hemisphere atmospheric circulation modulates all subtropical anticyclones' strength and position, linking all southern subtropical dipoles.
A large number of studies have dedicated their attention to show the relevance of SASD for South American and West African climate. Muza et al. (2009) have demonstrated correlations between SASD and extreme precipitation events in southwestern Brazil on interannual time scales. Bombardi et al. (2014) have used rain gauge precipitation and satellite and reanalysis data to demonstrate that, during neutral ENSO events, SASD modulates cyclogenesis and the characteristics of the South Atlantic convergence zone (SACZ), organizing convection and increasing precipitation over eastern South America. Furthermore, correlations between SST anomalies in the South Atlantic with SACZ position and strength are suggested in other studies (Taschetto and Wainer 2008; Zhou and Lau 1998; Chaves and Nobre 2004; Bombardi et al. 2013; Robertson and Mechoso 2000), which has amplified the SASD relevance for climate, as the SACZ is a key component for the monsoons and rainy season over southwestern Brazil (Zhou and Lau 1998; Carvalho et al. 2002a,b; Chou and Neelin 2001).

The influence of SST anomalies over West Africa has also been largely explored. In the past few years, a new interpretation of South Atlantic climate has arisen, with great impact for SASD studies. Nnamchi and Li (2011) have studied links between precipitation over West Africa and the South Atlantic dipole. They have suggested not only that West African precipitation is linked to dipole events, but also that the influence of Atlantic Niños on Guinea Coast precipitation is, actually, due to the dipole itself. In Nnamchi et al. (2016) the authors have used reconstructed SST from different sources to reinforce their previous statement, that Atlantic Niños might be the northern expression of the austral winter SASD variability. Richter et al. (2010) have compared remote equatorial forcings versus local influences on triggering Benguela Niños, suggesting that meridional wind anomalies, associated with a weaken subtropical anticyclone, substantially contribute to those SST anomalies. Lübbecke et al. (2010) have compared Atlantic and Benguela Niños, suggesting that they are strongly correlated, and also pointed the influence of the subtropical anticyclone on SST anomalies in eastern tropical Atlantic. Focusing on impacts of the Atlantic Niño, Losada et al. (2010) have used four AGCMs with prescribed SST to analyze the atmospheric response from tropical SST anomalies, suggesting that most of the summer West African rainfall variability is coupled to the Atlantic Niño. Vizy and Cook (2001) have used GCM simulations, with prescribed SST, describing that this link between SST and precipitation is due to large-scale circulation and atmospheric moisture anomalies, and that rainfall over West Africa is less sensitive to cold SST anomalies on the northeast winter SASD region. A similar approach is used in Kucharski et al. (2009), 


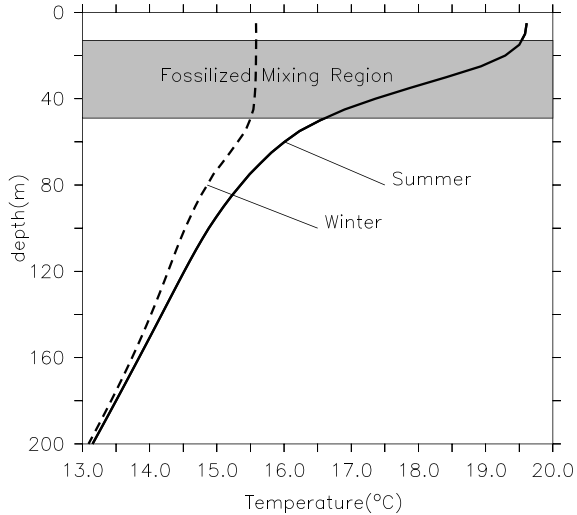

(a)

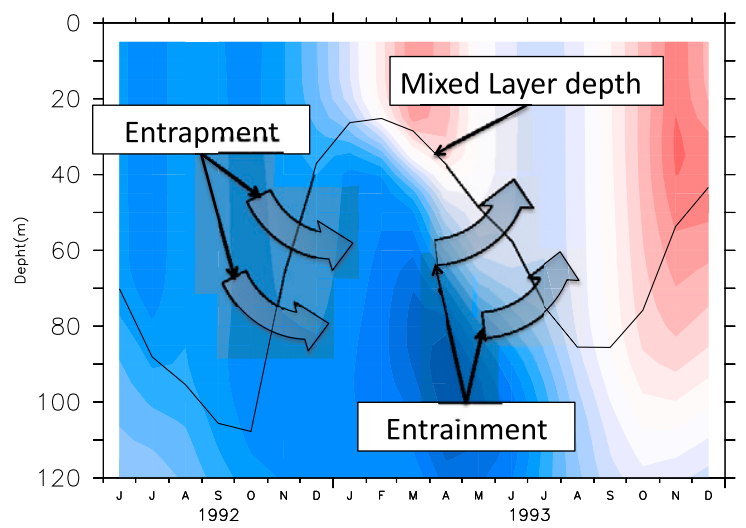

(b)

FIG. 1. (a) Averaged temperatures from ATI0.08 in the central South Atlantic for austral summer (solid) and winter (dashed). The gray background represents the fossilized mixing region, enclosed between the summer and winter mixed layer depths. (b) Temperature anomalies (colored background) and the mean mixed layer depth (solid line), both from the ATI0.08 experiment, averaged within the northeast SASD pole, from July 1992 until December 1993. The tilted arrows denote the anomalies entrapment and entrainment.

where it is suggested that SST anomalies in the tropical Atlantic impacts in both West African and Indian monsoons through a Gill-Matsuno-type teleconnection mechanism (Matsuno 1966; Gill 1980). Kucharski et al. (2009), on the other hand, have pointed that climate models present difficulties when trying to correctly reproduce the Sahel rainfall and have significant biases in the tropical Atlantic. Nevertheless, the links between South Atlantic, tropical Atlantic, and West African climate have great support in observational and modeling studies (Nicholson and Webster 2007; Polo et al. 2008; Nnamchi and Li 2011; Richter et al. 2010; Wagner and da Silva 1994; Ward 1998; Lübbecke et al. 2010, 2014; Richter et al. 2010; Rouault et al. 2018; Haarsma et al. 2003; Robertson et al. 2003). These results suggests that the SASD and its seasonality deserve great attention.

A relevant difference between summer and winter SASD events would be the mixed layer thickness over which the temperature anomalies are formed. In the OGCM hindcast experiment used here (Castellanos et al. 2016), the summer mixed layer is approximately $17 \mathrm{~m}(37 \mathrm{~m})$ thick in the southwestern (northeastern) SASD pole, as opposed to $80 \mathrm{~m}$ thick during winter (in both poles). It suggests that a winter SASD event prints its temperature anomaly in a much thicker layer.

On the other hand, through the mixed layer seasonal cycle, when it begins to get shallower, as summer approaches (see Fig. 1a), the waters with winter-spring properties are left below the summer mixed layer, trapped in a fossilized mixing region (Tomczak and Godfrey 1995). Depending on the Ekman pumping, which is positive under the subtropical high, the fossilized water will be captured by the mixed layer as it begins to sink in next autumn, or is injected into the ocean interior. It raises the question whether the formation of the fossilized mixing region might also capture anomalies from an austral winter SASD, and how those trapped anomalies would evolve. In this study, we have investigated the hypothesis that an austral winter-spring SASD event introduces anomalies in the fossilized mixing region, which would feed back onto SST or impact the mixed layer thickness. A schematic plot of this mechanism is in Fig. 1b. We have focused our analysis on the austral climate, so the austral terminology is then implicit.

The remainder of this study is divided as follows: In section 2 we describe the numerical model and the experiments setup. In section 3 , the results from all numerical experiments are presented and analyzed. The conclusions are in section 4.

\section{Numerical model}

The Hybrid Coordinate Ocean Model (HYCOM; Bleck 2002) is a primitive-equation OGCM evolved from the Miami Isopycnic-Coordinate Ocean Model (MICOM; Smith et al. 1990). It has the ability to interchange the vertical coordinates between isopycnal, terrain-following, or $z$-level, optimizing its applicability to near-bottom, ocean interior, and near-surface processes. Vertical mixing is represented by $K$-profile parameterization (KPP) (Large et al. 1994). A second-order advection scheme is adopted in the momentum equation, with no-slip conditions and a deformation-dependent Laplacian viscosity. 


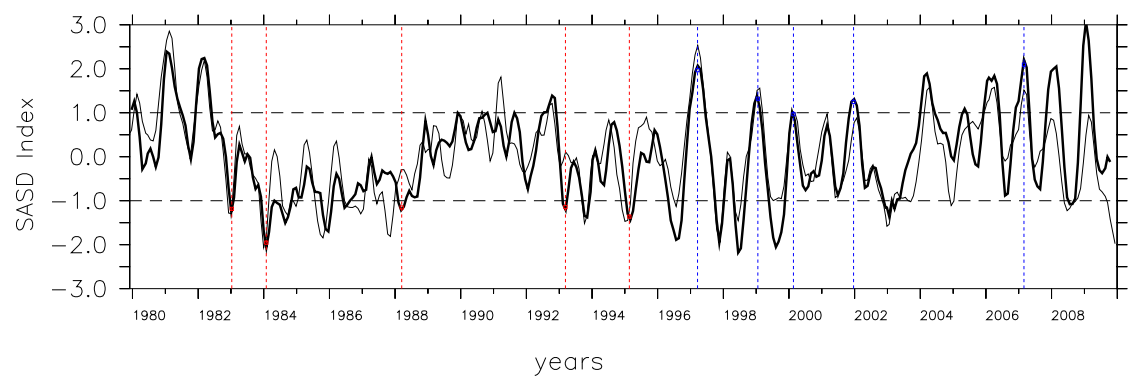

FIG. 2. Normalized SASDI, with SST from ATI0.08 (thick lines) and NOAA ERv05 (thin lines). The dashed red and blue lines denote the negative and positive SASD events selected, respectively.

Density is calculated according to a sigma- $t$ scheme, in which only temperature and salinity are taken into account, making the model appropriate for upper-layer studies (upper $2000 \mathrm{~m}$ ).

\section{a. Experiment setup}

We have used results from a hindcast experiment with HYCOM, hereafter referred to as ATI0.08, described in detail and validated in Castellanos et al. (2016). The ATI0.08 has $1 / 12^{\circ}$ horizontal resolution and 22 hybrid vertical layers, with a domain that spans $50^{\circ} \mathrm{S}-20^{\circ} \mathrm{N}$, $80^{\circ} \mathrm{W}-40^{\circ} \mathrm{E}$. The ATI0.08 was forced, from 1960 to 2010, with monthly means from NCAR-NCEP reanalysis products (Kalnay et al. 1996). Castellanos et al. (2016) have used statistical analyses and model-data intercomparisons to show that the ATI0.08 was able to reproduce large-scale and mesoscale dynamics, as well as the seasonal and annual variability of the South Atlantic.

With ATI 0.8 outputs, 10 austral summer SASD events were selected between 1980 and 2010, five events for each SASD phase (Fig. 2). The criteria for selection use the SASD index (SASDI; the SST anomalies averaged within $30^{\circ}-40^{\circ} \mathrm{S}, 10^{\circ}-30^{\circ} \mathrm{W}$ minus those averaged within $\left.15^{\circ}-25^{\circ} \mathrm{S}, 0^{\circ}-20^{\circ} \mathrm{W}\right)$ to find events in which the index exceeds \pm 1 standard deviation during December-March (DJFM). Among all candidates, the selected events were cast arbitrarily, mixing marginal and stronger events to be the subject of a series of sensitivity tests. For each austral summer SASD selected, a series of simulations were performed, designed to evaluate the impacts of a previous winter-spring SASD event on the selected summer SASD. The SASDI with SST from NOAA-ERv5 (Huang et al. 2017) is included in Fig. 2 for comparison. With exception of the SASD event in 1988, all events are in good agreement with observations. The experiments performed in this study were designed to assess the impacts of prescribed anomalies rather than to reconstruct a realistic hindcast. They are compared to a control run performed with the same model. Thus, the 1988 case and also the order each event was selected should not interfere in the results.

Two different experiment designs are used. The first introduces temperature anomalies directly in the fossilized mixing region. In these experiments, temperature anomalies and their entrapment were prescribed. These experiments are referred to as $\mathrm{OCN}$ experiments or OCNs. The second introduces anomalies in the atmospheric wind field. Here, the formation and entrapment of temperature anomalies are simulated. These experiments are referred to as ATM experiments or ATMs.

The new experiments were all performed in a smaller domain, hereafter referred to as ATL0.25, which covers only the region where the SASD is most relevant (see Fig. 3), with $1 / 4^{\circ}$ horizontal resolution. ATI0.08 provides both initial and boundary conditions for all new experiments with ATL0.25. The coarser resolution of ATL0.25 is within the resolutions used in previous modeling studies (MK11; Morioka et al. 2014; Haarsma et al. 2005). It is refined enough to reproduce the SASD physics, which allow us to perform different ensembles with a great number of experiments. The atmospheric forcing fields are the same as in ATI0.08, from the NCEP-NCAR reanalysis. All other parameters are set as in ATI0.08.

\section{b. Methodology of the OCN experiments}

The OCN experiments, with anomalies introduced directly into the fossilized mixing region, aim to explore the effects that prescribed temperature anomalies, trapped below the summer mixed layer, have in SST.

Temperature anomalies prescribed in OCNs are defined as the second EOF analysis of SST [EOF2(SST)], from ATI0.08 (Fig. 3a), which represents the averaged SST SASD signal. The EOF2(SST) is then multiplied by a dimensionless vertical weight function (Fig. 3b), which is set to zero everywhere except in the fossilized mixing region, where it assumes amplitudes of $A=$ $\{-3,0,3\}$. These amplitudes were chosen based on 
a) EOF2 of SST from ATIO.08

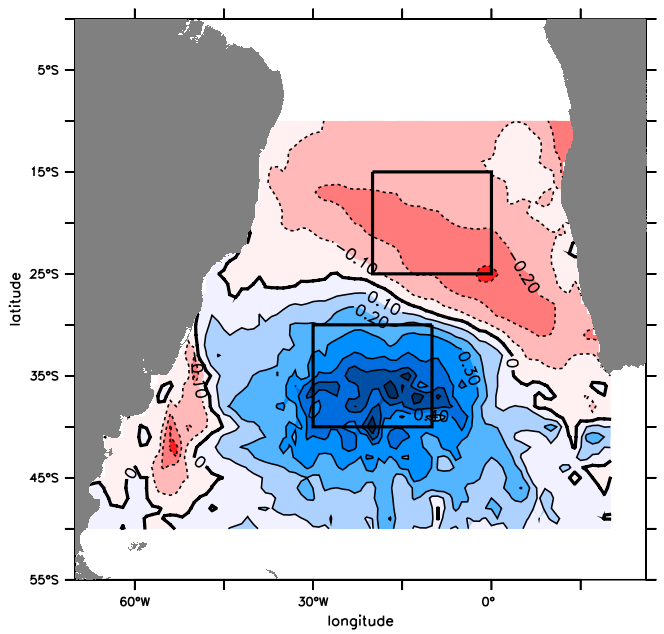

b) Vertical weight function at one grid point

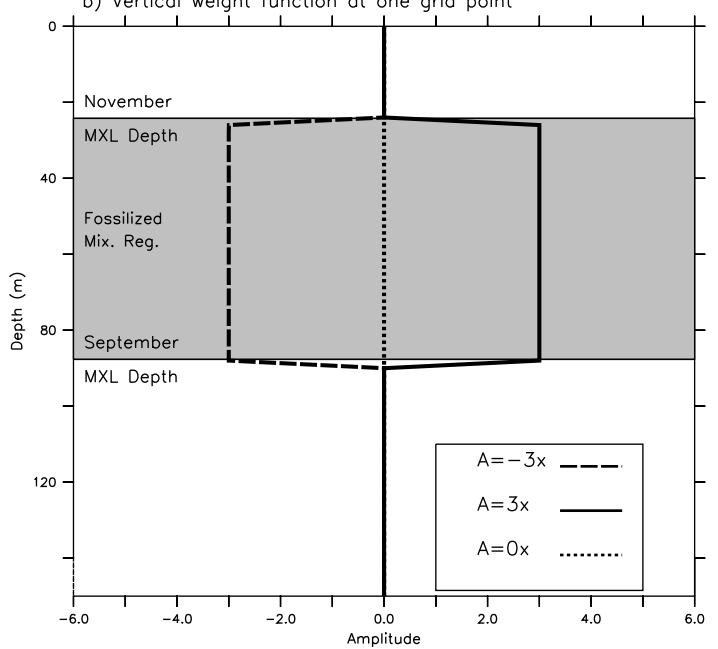

FIG. 3. (a) The EOF2(SST) $\left({ }^{\circ} \mathrm{C}\right)$ from ATI0.08. Only values greater in magnitude than 0.1 are considered. The boxes in (a) denote the areas where the SASDI is calculated. (b) The vertical weight function for experiments $3 \times$, $0 \times$, and $-3 \times$. The gray background denotes the averaged fossilized mixing region, defined, at each grid point, as the layer between the mixed layer depth from September to November.

the expansion coefficients of EOF2(SST), which peak near \pm 3 . Thus, the SST anomalies represent extreme situations captured by EOF analysis, but still within observed variability. Maximum anomalies are approximately $\pm 1.8^{\circ}$ and $\pm 0.9^{\circ} \mathrm{C}$ in the southwest and northeast poles, respectively. A similar approach was used by Haarsma et al. (2003) and Robertson et al. (2003). They have used SVD and EOF analyses to capture the leading SST variability modes, and then forced atmospheric models with those anomalies. Here, instead, we use SST anomalies in the ocean model itself. The entrapment of temperature anomalies in the fossilized mixing region occurs during the mixed layer rising from its deeper (near September) to shallower (near November) position (see Fig. 1b). Thus, the fossilized mixing region is defined here as the layer between the mean mixed layer depth of September and November, at each grid point.

All experiments cover a time span less than 2 years; thus, we refer to the first year of integration by the suffix (0) and to the second year by the suffix (1). All experiments in the OCNs start in early November(0), with a specific temperature anomaly $\left(T_{\text {Anomaly }}=A \times\right.$ EOF2 $\left.{ }_{\mathrm{SST}}\right)$ in the fossilized mixing region, and are integrated until December(1); there is a total of 30 experiments. To prevent model instability, before adding the prescribed anomalies, all temperature anomalies were removed from the initial condition file. This procedure was only applied in the fossilized mixing region, and only at the grid points where the EOF2(SST) is greater than $0.1^{\circ} \mathrm{C}$, in magnitude, restricting modifications to the area where the SASD is most significant. Hence, in this area, the new model temperature is the mean temperature from November plus the prescribed temperature anomaly. Such procedure might diverge the model solution from the original run (ATI0.08), hence, the $0 \times$ experiments were run to be the new control run, where the previous temperature anomalies were removed but no prescribed anomaly was added.

\section{c. Methodology of ATM experiments}

In ATM experiments, instead of introducing temperature anomalies in the fossilized mixing region, prescribed anomalies were introduced in the surface wind field. These anomalies are the wind at $10 \mathrm{~m}$ composed for positive and negative SASD phases (composed when SASDI exceeds \pm 1.5 standard deviation), (Figs. 4a,b). These composites were added to the original wind field with a pulse function, starting in June(0) until October(0), peaking in August(0) (Fig. 4c). Thus, for each SASD event selected in the ATI0.08 (Fig. 2), the new simulations were started in early June $(0)$ and integrated until December(1), while anomalies in the wind field were applied from middle June(0) to October(0). The pulse function amplitude was set to $A=3$ [the extreme values of EOF1(SLP) expanded coefficients], which controls the anomaly intensity, while its phase was given by the composite phase. Additionally, for each SASD event, a control simulation was run with $A=0$. Thus, for each SASD event selected in ATI0.08, three new simulations were performed in ATM experiments: one for each SASD 
a) Anomaly of wind at $10 \mathrm{~m}$ from Positive SASD

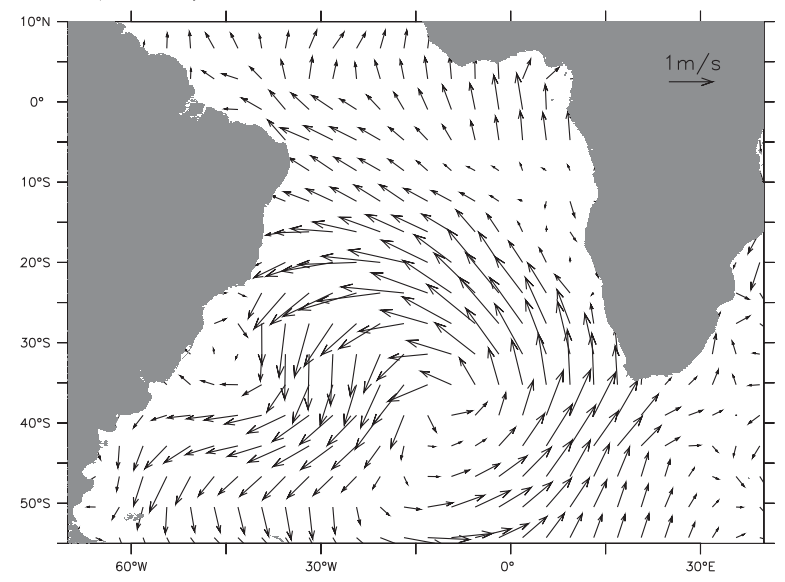

b) Anomaly of wind at $10 \mathrm{~m}$ from Negative SASD

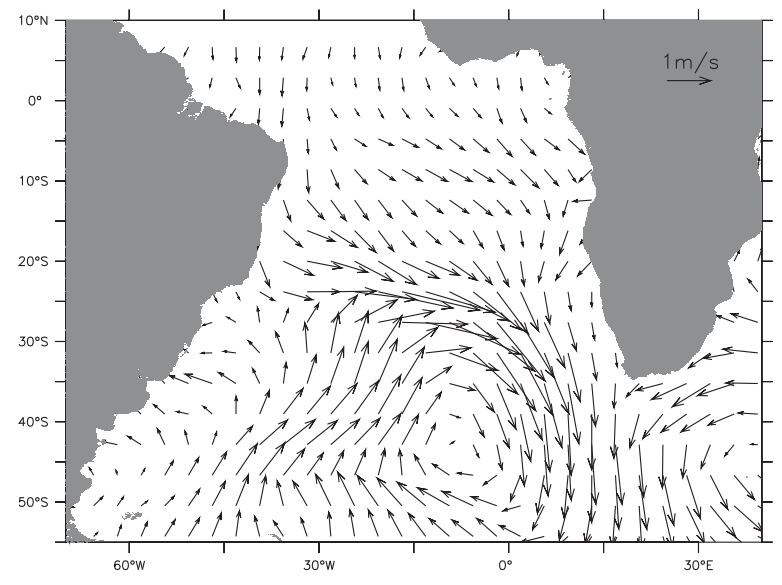

c) Time weights

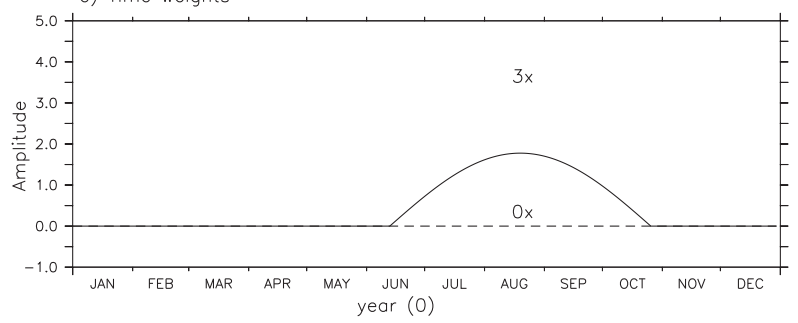

FIG. 4. Wind at $10 \mathrm{~m}$, from NCEP-NCAR, composed for (a) positive and (b) negative SASD events from ATI0.08. The composing criteria is the SASDI, from 1980 to 2010, exceeding \pm 1.5 standard deviation. (c) The pulse function used to add the wind anomalies in the atmospheric forcing.

phase, with $A=3$, and a control run with $A=0$; there is a total of $30 \mathrm{ATM}$ experiments.

\section{Results}

\section{a. Results from OCN experiments}

Figure 5 shows the SASDI anomaly, calculated as the SASDI from each experiments $A=3(3 \times)$ and $A=-3$
$(-3 \times)$ minus the SASDI from experiments $A=0(0 \times)$ Between December(0) and February(1), SASDI anomalies are small and approximately constant, suggesting that the anomalies we have introduced assert little influence on overlying SST in this period. After March(1), anomalies start to grow in magnitude until August(1), then they start to weaken until November(1). The signal of these anomalies is consistent with the SASD anomaly signal we have introduced in the fossilized mixing region in November(0). In other words, a positive (negative) SASD anomaly, when trapped in the fossilized mixing region in November $(0)$, creates, in winter(1), an anomaly consistent with a positive (negative) SASD.

This suggests a memory effect, which brings to the winter-spring(1) temperature anomalies from last winter-spring $(0)$. This is observed in all 10 events investigated (Fig. 5), suggesting a response that is independent of the SASD phase in summer(0-1), and also independent of winter(1)-spring(1) conditions.

Figure 6 a shows the mean SST anomalies $(3 \times$ minus $-3 \times$ experiments) for August(1), when the memory effect in SASDI (Fig. 5) is most evident. SST anomalies follow the SASD pattern, with well-defined southwest pole anomalies and weak and scattered anomalies in the northeast region. Reasons for this asymmetry are discussed latter. This indicates that, whether a winter(0)-spring $(0)$ SASD prints its anomalies in the fossilized mixing region, they will feed back to SST in winter(1), especially in the southwest region, changing the SST in a wide region of the South Atlantic. A SASD pattern is also observed in mixed layer depth anomalies (Fig. 6b), but with strong positive (deeper) and negative (shallower) anomalies in the southwest and northeast poles, respectively. These anomalies, of mixed layer thickness of August(1), are the opposite of those directly caused by an austral summer SASD (MK11), where positive (negative) SST anomalies are associated with a shallower (deeper) mixed layer. This difference is caused because here temperature anomalies are, actually, below the mixed layer, within the fossilized mixing region. In other words, a positive temperature anomaly within (below) the mixed layer will enhance (weaken) stratification, making it shallower (deeper). Coherently, a negative temperature anomaly within (below) the mixed layer will weaken (enhance) stratification, making it deeper (shallower). These results suggest that the memory effect not only might feedback to the atmosphere, through anomalies of SST, but also might affect properties of water subducted under the subtropical anticyclone, by its impacts in the amplitude of the mixed layer interannual variability (Tomczak and Godfrey 1995).

The process that governs SST anomalies involved in this memory effect is summarized in the mixed layer 


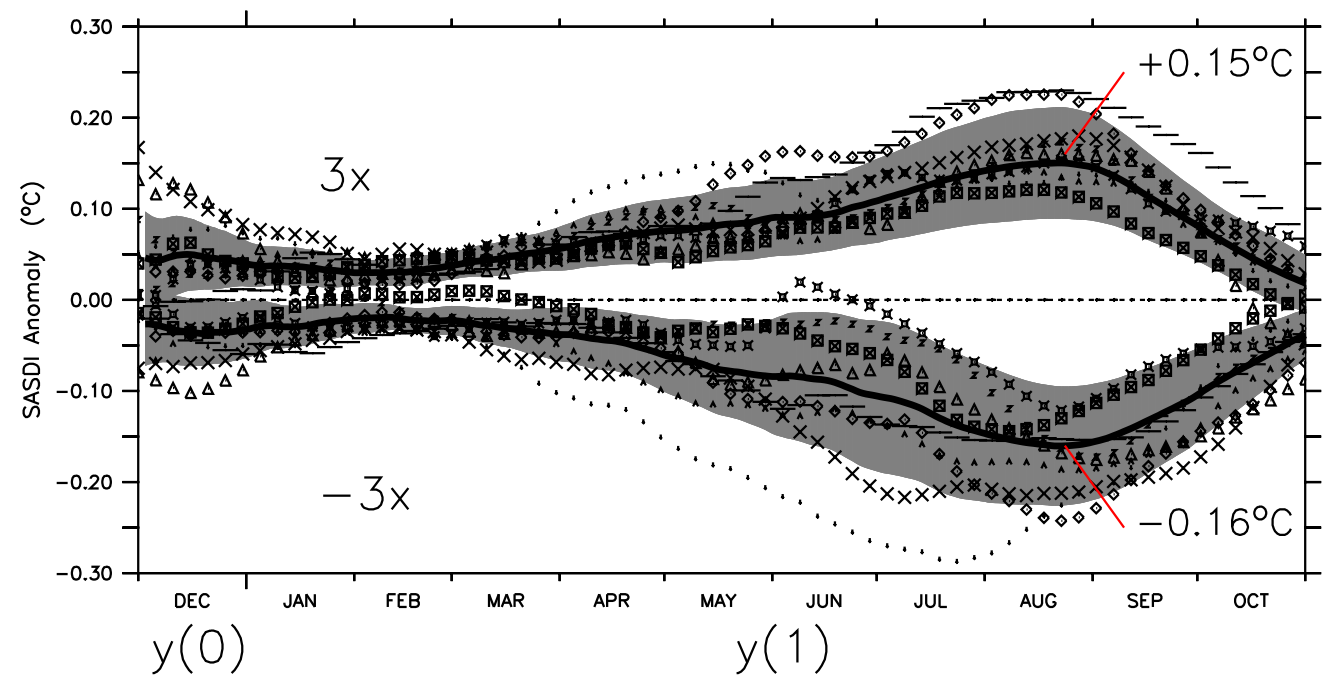

\begin{tabular}{|lll|}
\hline overage & & \\
2006 & $\star$ & $\star$ \\
2001 & $\star$ & $\star$ \\
1999 & $\times$ & $\times$ \\
1998 & $\bullet$ & $\bullet$ \\
1996 & $\star$ & $\star$ \\
1994 & $\Delta$ & $\Delta$ \\
1992 & $*$ & $*$ \\
1987 & + & + \\
1983 & - & - \\
1982 & $\times$ & $\times$ \\
\hline
\end{tabular}

FIG. 5. SASDI anomalies $\left({ }^{\circ} \mathrm{C}\right)$ for OCN experiments, for all $3 \times(3 \times$ minus $0 \times)$ and $-3 \times(-3 \times$ minus $0 \times)$ experiments. The black lines denote the average of each group and the gray background denotes \pm 1 standard deviation.

temperature tendency equation [Eq. (1)] (MK11; Qiu and Kelly 1993; Moisan and Niiler 1998):

$$
\frac{\partial T_{m}}{\partial t}=\frac{Q_{\mathrm{net}}-q_{d}}{\rho c_{p} H}-\mathbf{u}_{m} \cdot \nabla T_{m}-\frac{\Delta T}{H} w_{e}+\text { Res. }
$$

The term on the left-hand side is the mixed layer temperature $\left(T_{m}\right)$ tendency. The first term on the right-hand side is the contribution from surface net heat flux (NHF; $Q_{\text {net }}$ ), where $q_{d}$ is the downward insolation through the bottom of the mixed layer, $\rho$ is the mean mixed layer density, $c_{p}$ is the specific heat of the seawater, and $H$ is the mixed layer depth, defined as the depth at which a jump in density equivalent to $0.2^{\circ} \mathrm{C}$ has occurred. The value of $q_{d}$ is obtained by the vertical attenuation given by a type- 1 Jerlov type of water (Jerlov 1951). The second term on the right-hand side is the contribution from horizontal advection, where $\mathbf{u}_{m}$ denotes the mean mixed layer horizontal velocities, and $\nabla T_{m}$ is the horizontal temperature gradient. The third term is the contribution from entrainment, representing the process in which waters enters in the mixed layer from below. Also, $\Delta T$ is the mixed layer temperature $\left(T_{m}\right)$ minus the temperature $20 \mathrm{~m}$ below the base of the mixed layer (MK11). Finally, $w_{e}$ is the entrainment velocity, given by a) SST anomaly in August ( $y 1$ )

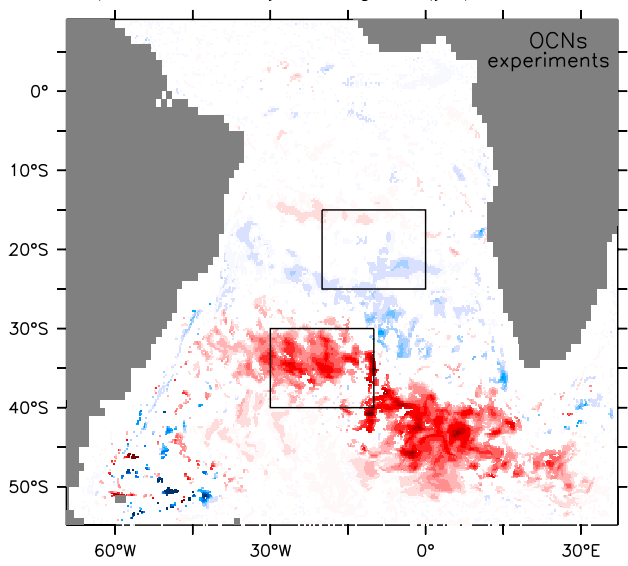

b) $M X L$ depth anomaly in August ( $y 1$ )

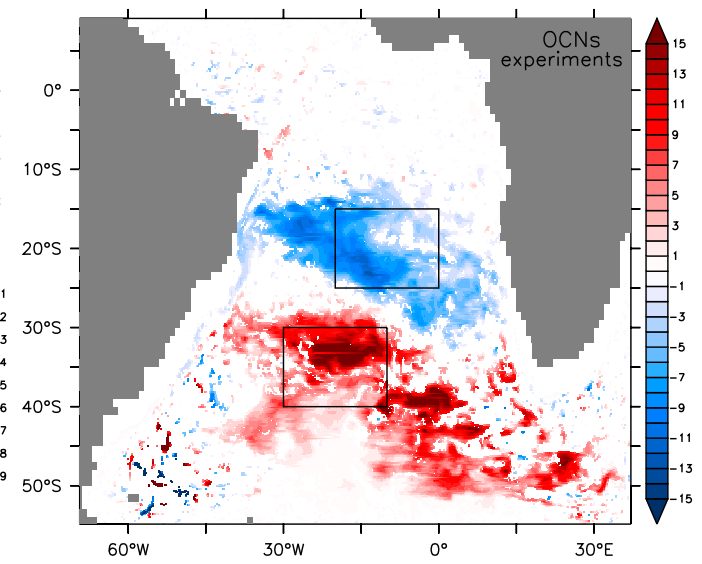

FIG. 6. The departure, $3 \times$ minus $-3 \times$, of (a) $\operatorname{SST}\left({ }^{\circ} \mathrm{C}\right)$ and (b) mixed layer depth $(\mathrm{m})$, in the OCN experiment, averaged in August(1). Only results exceeding the $90 \%$ confidence level are shown, according to a sign test (Anderson and Finn 1996), applied to August(1). 
a) Southwest Pole (3x experiments)

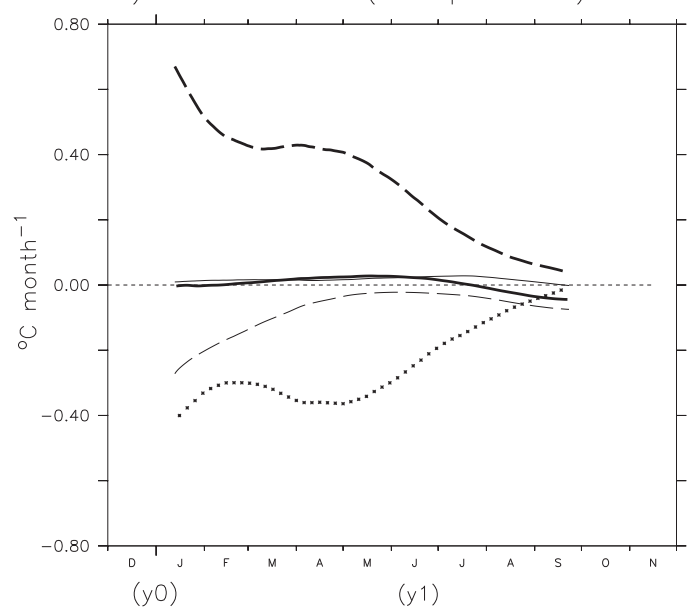

c) Southwest Pole ( $-3 \times$ experiments)

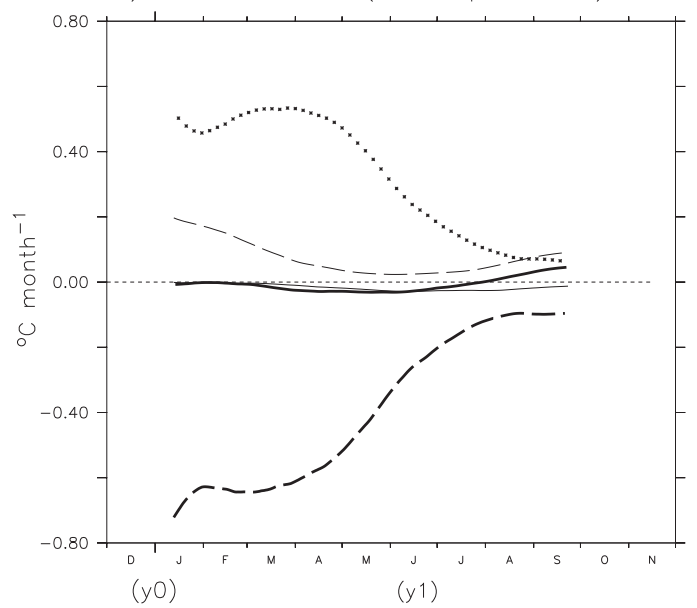

b) Northeast Pole (3x experiments)

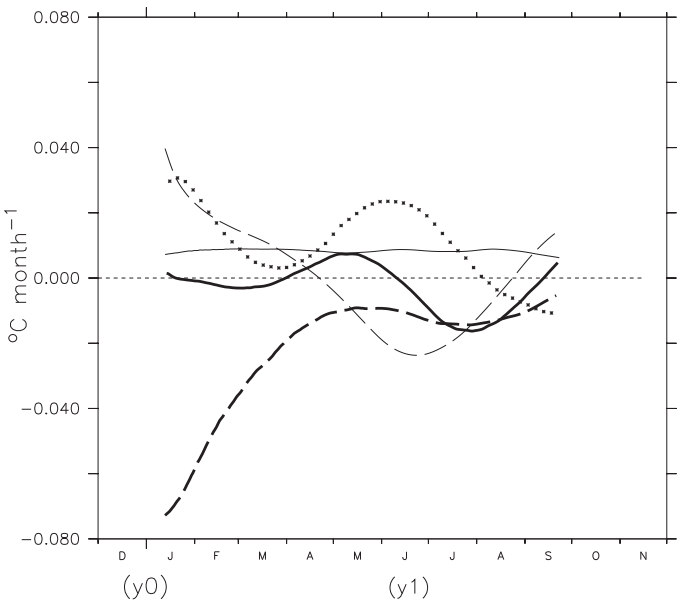

d) Northeast Pole ( $-3 \times$ experiments)

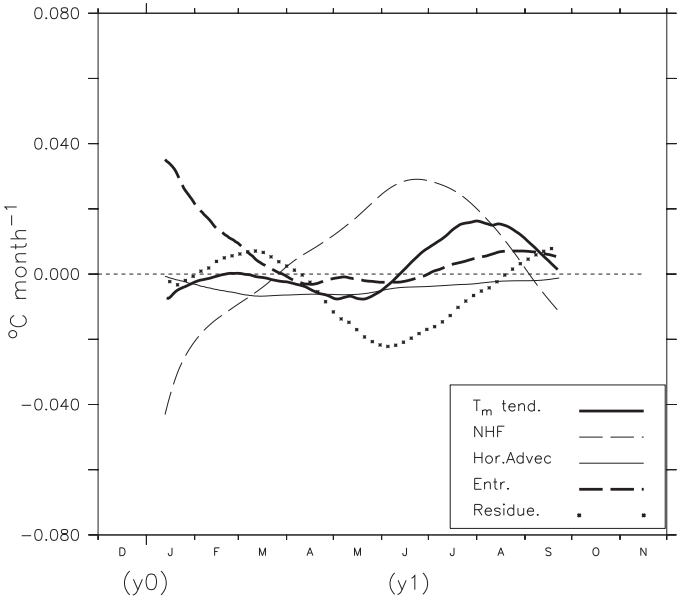

FIG. 7. The averaged anomalies of all terms in Eq. (1) $\left({ }^{\circ} \mathrm{C}\right.$ month $\left.{ }^{-1}\right)$ for the OCN experiments (a),(b) $3 \times$ and (c),(d) $-3 \times$, averaged within the (a),(c) southwest and (b),(d) northeast poles. The northeast region is enclosed by $15^{\circ}-25^{\circ} \mathrm{S}, 0^{\circ}-20^{\circ} \mathrm{W}$, and the southwest region is within $30^{\circ}-40^{\circ} \mathrm{S}, 10^{\circ}-30^{\circ} \mathrm{W}$. The anomaly is calculated by subtracting the results of the $0 \times$ experiment from the $3 \times$ and $-3 \times$ experiments.

$$
w_{e}=\frac{\partial H}{\partial t}+\nabla \cdot\left(\mathbf{u}_{m} H\right)
$$

The entrainment velocity is set to zero when $w_{e}$ is less than zero, since only waters entering the mixed layer will change its temperature. The terms not included in Eq. (1) (e.g., diffusion, turbulent mixing, and highfrequency variability not resolved in the time series analyzed here) are represented as a residual term (Res). A 3-month running mean is applied to smooth all time series.

\section{1) Southwest POLE (OCNs)}

In these calculations, both southwest and northeast poles are the same as in SASDI calculation, and thus they are set according to the original SASD spatial distribution rather than positioned over specific areas where the memory effect is most intense. This choice comes from the focus given to the entrapmententrainment mechanisms due to the SASD original anomalies.

Figure 7 shows the averaged anomalies of each term from Eq. (1), for all experiments $3 \times$ (top panels) and $-3 \times$ (bottom panels), over the southwest (left panels) and northeast (right panels) SASD poles. The southwest pole presents anomalies that are about 10 times those in the northeast pole; thus, the scaling of the vertical axis is different between the left and right panels. The term "anomaly" is used here, and in the further analysis, to express the departure of each experiment from its control run $(0 \times$ experiment). When necessary, we explicitly present a different definition. 
a) Southwest Pole (3x experiments)

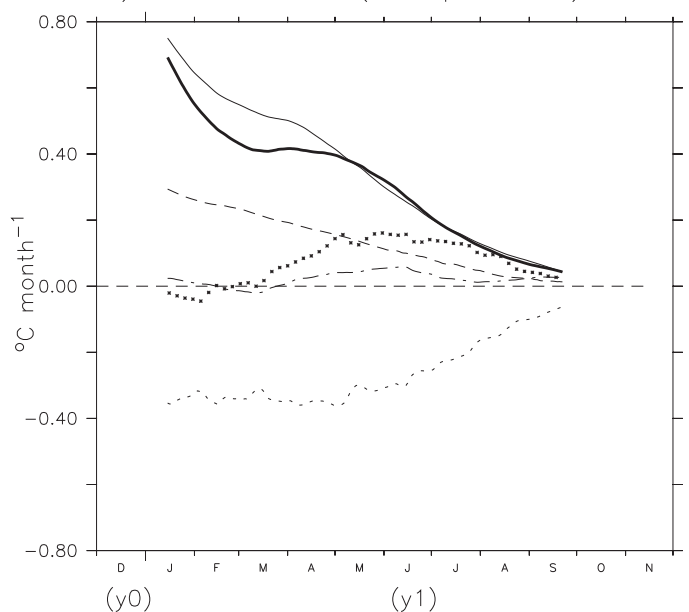

b) Southwest Pole ( $-3 x$ experiments)

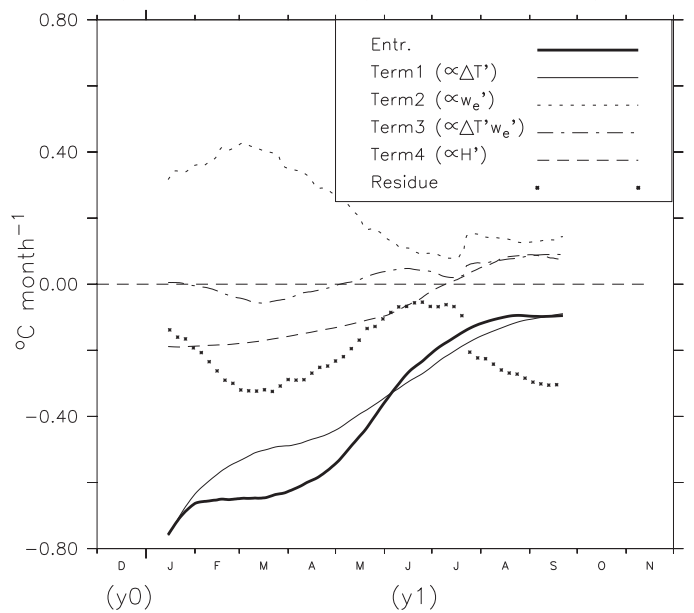

FIG. 8. The averaged anomalies of all terms in Eq. (3) $\left({ }^{\circ} \mathrm{C} \mathrm{month}^{-1}\right)$ for OCN experiments (a) $3 \times$ and (b) $-3 \times$, in the southwest pole.

In the southwest pole, the $3 \times(-3 \times)$ experiments present a positive (negative) temperature anomaly in the fossilized mixing region. Comparing the $T_{m}$ tendency between $3 \times$ and $-3 \times$, from early March(1) until $\operatorname{July}(1)$, it presents the same signal as the temperature anomalies underneath (Figs. 7a,c). In other words, when there are positive (negative) temperature anomalies in the fossilized mixing region, $T_{m}$ tendency anomalies will also be positive (negative), in March-July (MAMJJ), suggesting that the entrapped temperature anomalies are feeding back to SST. During this time, March(1) until July(1), the entrainment term is the dominant term contributing to the mixed layer temperature tendency, being most compensated by the residue terms. One possible explanation for this significant contribution from residue terms is that Eq. (1) does not include diapycnal diffusion, which is affected by variations in the vertical temperature gradient. The temperature anomalies introduced withing the fossilized mixing region are greater in the southwest pole, what may cause greater anomaly of vertical diffusion there.

Surface NHF acts in the opposite direction of entrainment, but with smaller amplitude. The direction of surface NHF contribution is consistent, since positive (negative) anomalies of SST (Fig. 6) increase (weaken) loss of latent and sensible heat to atmosphere.

To better understand the contribution of the entrainment term [the third term on the right-hand side of Eq. (1)], we expand this term around $H$ in a Taylor series, and decompose the terms $w_{e}=\overline{w_{e}}+w_{e}^{\prime}$ and $\Delta T=\overline{\Delta T}+\Delta T^{\prime}$, where the overbar $\overline{()}$ represents the control run and the prime ()$^{\prime}$ represents the departure from each experiment to its control run. Following this, anomalies of entrainment can be written as

$$
\operatorname{Ent}^{\prime}=-\frac{\Delta T^{\prime} \overline{w_{e}}}{\bar{H}}-\frac{\overline{\Delta T} w_{e}^{\prime}}{\bar{H}}-\frac{\Delta T^{\prime} w_{e}^{\prime}}{\bar{H}}+\frac{\overline{\Delta T} \overline{w_{e}} H^{\prime}}{\bar{H}^{2}}+\text { Res. }
$$

Figure 8 shows the anomalies of all terms on the righthand side of Eq. (3), averaged in the southwest pole. The anomalies in the entrainment are mostly due to anomalies in the vertical temperature gradient $\left(\Delta T^{\prime}\right)$, injected into the mixed layer by the mean vertical velocity $\left(\overline{w_{e}}\right)$. Anomalies of mixed layer thickness $\left(H^{\prime}\right)$ also contribute to entrainment in the same direction as the first term, by changing the layer thickness over which $\overline{\Delta T} \overline{w_{e}}$ acts. The second term $\left(w_{e}^{\prime}\right)$ acts in the opposite direction; however, it does not change the entrainment sign. Thus, in the southwest region, the entrapped temperature anomalies affect the vertical temperature gradient $\left(\Delta T^{\prime}\right)$ and mixed layer thickness $\left(H^{\prime}\right)$, leading to an entrainment that produces the memory effect in winter(1). Entrainment anomalies decrease with time, mostly due to the smoothed $\Delta T^{\prime}$, by enhanced entrainment, and the increase of $\bar{H}$ in winter (see the annual cycle of $\bar{H}$ in Figs. S3 and S4 in the online supplemental material). The second and third terms on the right-hand side of Eq. (3), representing turbulent and nonlinear contributions to $T_{m}$, are greater in the southwest pole, especially in August(1)-September(1); however, both have little influence on the entrainment term in $\mathrm{OCN}$ experiments. Entrainment is, thus, most controlled by $\Delta T^{\prime}$ and $H^{\prime}$ in OCNs. 
The contribution from the surface NHF [first term on the right side of Eq. (1)] is also expanded around $H$, and the separation $\overline{()}+()^{\prime}$ is applied, obtaining

$$
\mathrm{NHF}^{\prime}=-\frac{\overline{Q_{\mathrm{net}}}-\overline{q_{d}}}{\rho c_{p} \bar{H}^{2}} H^{\prime}+\frac{Q_{\mathrm{net}}^{\prime}-\overline{q_{d}}}{\rho c_{p} \bar{H}}+\text { Res. }
$$

In the southwest region, $H^{\prime}$ is positive (negative) in $3 \times$ $\left(-3 \times\right.$ ) experiments (Fig. 6), while $\overline{Q_{\text {net }}}$ is, on average, negative from April to August in these latitudes, when the ocean loses heat to atmosphere within the annual cycle. This leads to a positive (negative) contribution to $T_{m}$ in $3 \times(-3 \times)$ experiments by the first term on the right-hand side of Eq. (4). This mechanism is counterbalanced by contribution from $Q_{\text {net }}^{\prime}$, the second term of Eq. (4), which is negative (positive) over warmer (colder) SST due to enhanced (weakened) sensible and latent heat loss. In the southwest region, the contribution of $Q_{\text {net }}^{\prime}$ overcomes $H^{\prime}$ (see Figs. S1a,c in the online supplemental material), and thus the contribution from the surface NHF to the $T_{m}$ tendency anomaly is always negative (positive) in $3 \times(-3 \times)$ experiments (Figs. 7a,c).

\section{2) Northeast POle (OCNs)}

Anomalies obtained in the northeast SASD pole are weak; however, we present its result analysis since they are consistent with those from the ATM experiments.

Figures $7 \mathrm{~b}$ and $7 \mathrm{~d}$ show the anomalies of each term of Eq. (1), averaged in the northeast SASD pole. In this pole, $3 \times(-3 \times)$ experiments present a negative (positive) temperature anomaly in the fossilized mixing region. Entrainment is found consistent with those anomalies below the mixed layer in the beginning of experiments; however, it is compensated by surface NHF $(-3 \times)$ and the residual terms $(3 \times)$, and decreases rapidly until April(1).

The mechanism that produces the memory effect is present in the northeast region, producing a peak of $T_{m}$ tendency between July(1) and August(1). This is achieved by both entrainment and surface NHF contributions. In this case, decomposition of surface NHF [Eq. (4)] shows that contributions from $-H^{\prime} \overline{Q_{\text {net }}}$ act toward the restoration of the SASD anomalies between April(1) and August(1). The contribution from $Q_{\text {net }}^{\prime}$ does not counterbalance $-H^{\prime} \overline{Q_{\text {net }}}$, since SST anomalies are negligible in the northeast region in OCNs. Thus, contributions of surface NHF in the northeast pole are mostly due to an enhanced (weaken) effect of climatological heat loss in a thinner (thick) mixed layer (Figs. S1b,d). Decomposition of the entrainment term [Eq. (3)] shows that $\Delta T^{\prime}$ and the mixed layer thickness $\left(H^{\prime}\right)$ also contribute to in the direction of the memory effect, although the residue changes the signs of the entrainment contribution in $-3 \times$ experiments (Fig. 7d).

There are three possible reasons for the weaker anomaly in the northeast pole. The first is the mean Ekman pumping in the South Atlantic, which is on average stronger at the northeast SASD pole $(\approx-2 \times$ $\left.10^{-3} \mathrm{~kg} \mathrm{~m}^{2} \mathrm{~s}^{-1}\right)$ than the southwest pole $(\approx-1 \times$ $10^{-3} \mathrm{~kg} \mathrm{~m}^{2} \mathrm{~s}^{-1}$ ) (Tomczak and Godfrey 1995). As a result, temperature anomalies are introduced into the ocean interior faster in the northeast SASD pole (see Figs. S3 and S4), contributing to produce an asymmetry in entrainment between the two poles. The second reason is the SASD anomaly itself, represented by the EOF2(SST), which is weaker in the northeast pole (Fig. 3). Hence, anomalies introduced in the fossilized mixing region under this pole are weaker than those in the southwest pole. The third reason might be a problem in experiment design. In the northeast pole, the mixed layer of November has not achieved its shallowest depth yet. In November, the averaged mixed layer is about $69 \mathrm{~m}$ deep, and reaches near $44 \mathrm{~m}(30 \mathrm{~m})$ deep in December (January). Thus, the anomalies we have introduced in November(0) become too far from the bottom of the summer mixed layer, out of range to contribute to entrainment. In the southwest pole, the mixed layer reaches, on average, about $24 \mathrm{~m}(16 \mathrm{~m})$ deep in November (January); thus, our anomalies are closer to the mixed layer and easily contribute to entrainment in the southwest pole.

\section{b. Results from ATM experiments}

In ATM experiments, SST anomalies are forced by a prescribed SASD-like anomaly added in the wind field, from June(0) until September(0). The ocean responds with strong SST anomalies, peaking in September(0) and fading until January(1) (Fig. S2). SST anomalies, produced in JJA(0), are entrapped within the fossilized mixing region when the seasonal mixed layer becomes shallower [November(0)-January(1); Figs. S5 and S6], and feed back to SST in autumn(1). This is captured by SASDI anomalies in Fig. 9. Due to the anomalous wind forcing, SASDI anomalies peak near September(0), decreasing until January(1). After March(1), there is an increase in SASDI anomalies, noticeable between July(1) and August(1). This peak, in July(1)-October(1), is, in average, $10 \%$ of the peak in August(0)-October(0) [ASO(0)], while, in comparison, anomalies from OCN experiments in JJA(1) represent $27 \%$ of the peak in ASO(0). This reflects that, in OCNs, the entrapment is prescribed, whereas in ATMs it is simulated, and the subject of attenuation.

Figure 10 shows both SST and mixed layer thickness anomalies (here, anomaly means $3 \times$ minus $-3 \times$ experiments), averaged in August(1). Comparing these 


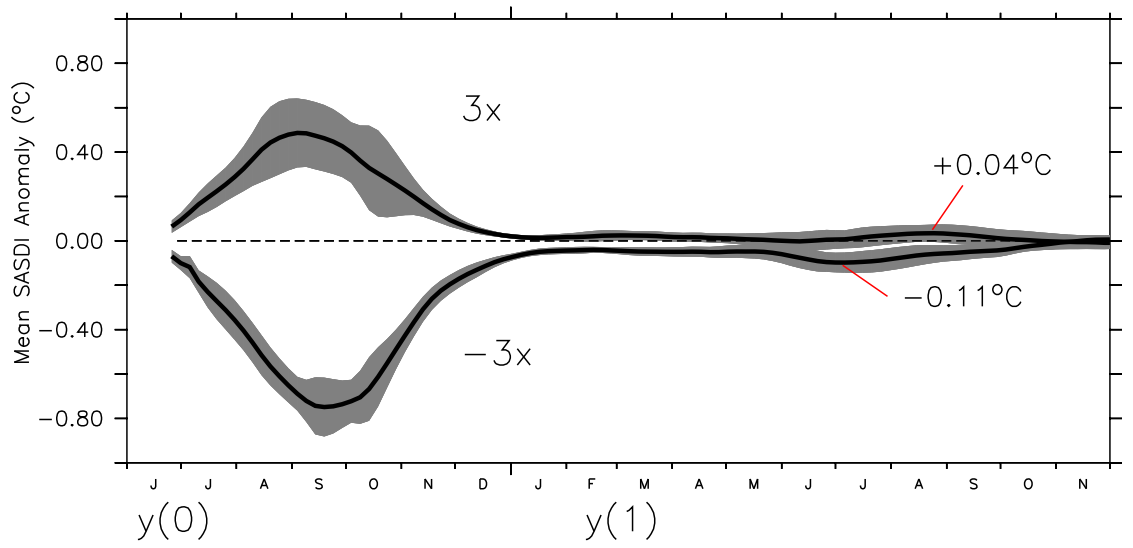

FIG. 9. Averaged SASDI anomalies (thick solid line; ${ }^{\circ} \mathrm{C}$ ) for ATM $3 \times$ and $-3 \times$ experiments. Gray background denotes \pm 1 standard deviation.

results with those from OCN experiments (Fig. 6), there is a weakening of the southwest pole in terms of both temperature and mixed layer thickness anomalies in ATMs, while the northeast pole presents a discrete intensification. The weakening in the southwest pole anomalies is the responsible for the smaller SASDI anomalies in JJA(0) in ATMs (comparing Figs. 5 and 9). In both poles, mixed layer anomalies signs are consistent with those from OCN experiments, caused by temperature anomalies being below the mixed layer (within fossilized mixing region). Although the smaller amplitudes, the dipole-like anomaly is present and statistically significant in ATMs, in both SST and mixed layer anomalies (Fig. 10), confirming the memory effect between the winter-spring SASD of consecutive years.

Comparing the maximum temperature anomalies $(3 \times$ minus $-3 \times)$ within the fossilized mixing region of
OCNs and ATMs, on $1 \mathrm{May}(1)$, it is, on average, $1.7^{\circ} \mathrm{C}$ $\left(-1.0^{\circ} \mathrm{C}\right)$ for the southwest(northeast) pole in OCNs, and $0.3^{\circ} \mathrm{C}\left(-0.7^{\circ} \mathrm{C}\right)$ for the southwest (northeast) pole in ATMs. This suggests that the smaller the memory effect in the southwest pole of ATM is, at least in part, due to the smaller anomalies within the fossilized mixing region. In the northeast pole, on the other hand, although there is a smaller anomaly in ATMs, we observe a small intensification in the memory effect, probably because in ONCs the prescribed temperature anomalies are too far from the mixed layer bottom to efficiently contribute to entrainment.

In ATM experiments, before calculating the contribution of each term from Eq. (1) to SST anomalies, we shifted southeastward the southwest pole, since part of the original pole lies in an area where the imposed wind anomalies produce a characteristic response of
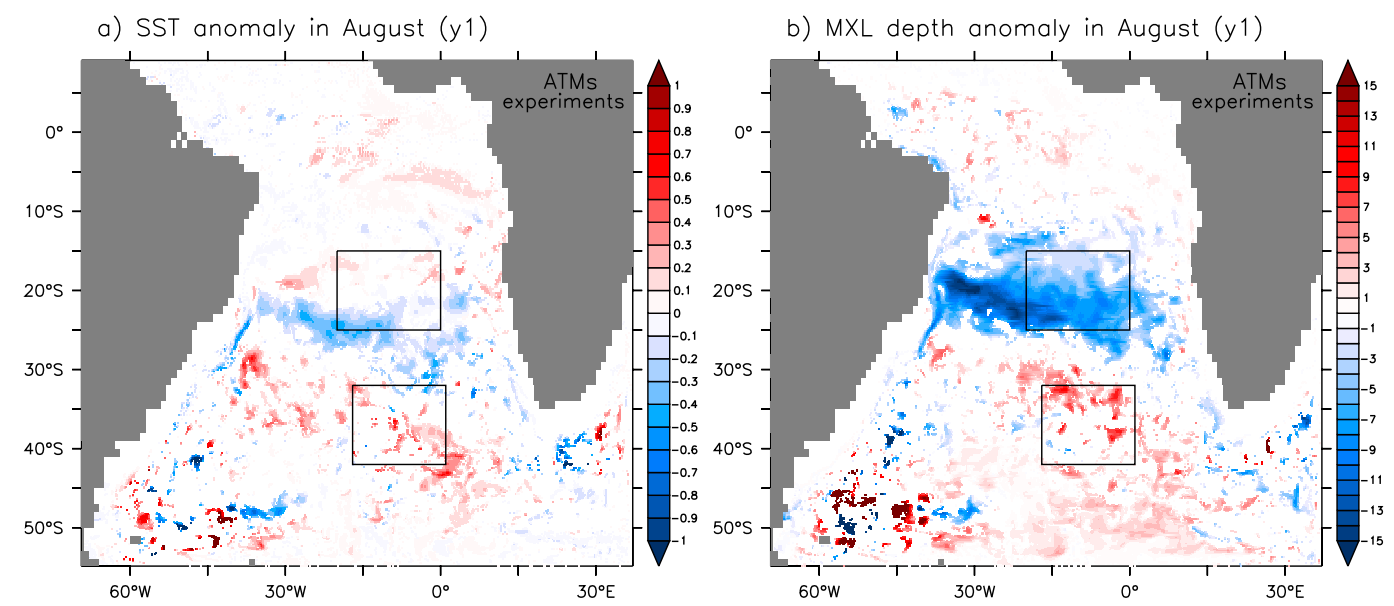

FIG. 10. As in Fig. 6, but for the ATM experiments. The boxes represent the regions where the northeast and the southwest SASD poles are studied in the ATM experiments. Only results exceeding the $90 \%$ confidence level are shown, according to a sign test (Anderson and Finn 1996), applied to August (1). 
a) Southwest Pole ( $3 x$ experiments)

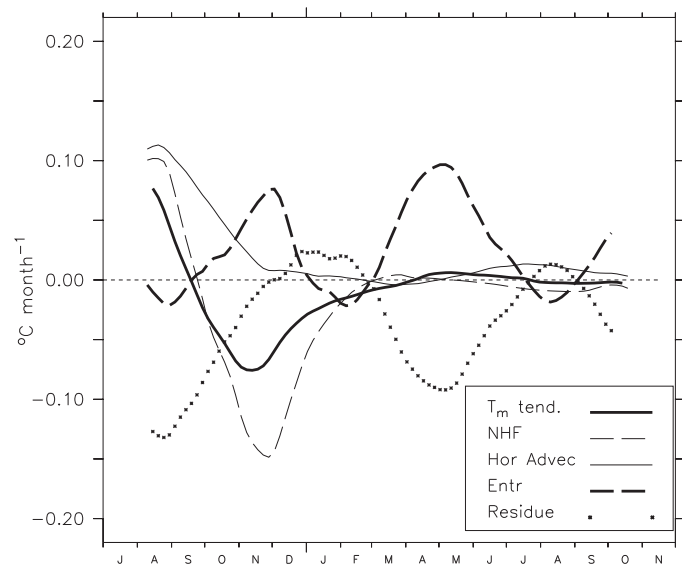

c) Southwest Pole ( $-3 x$ experiments)

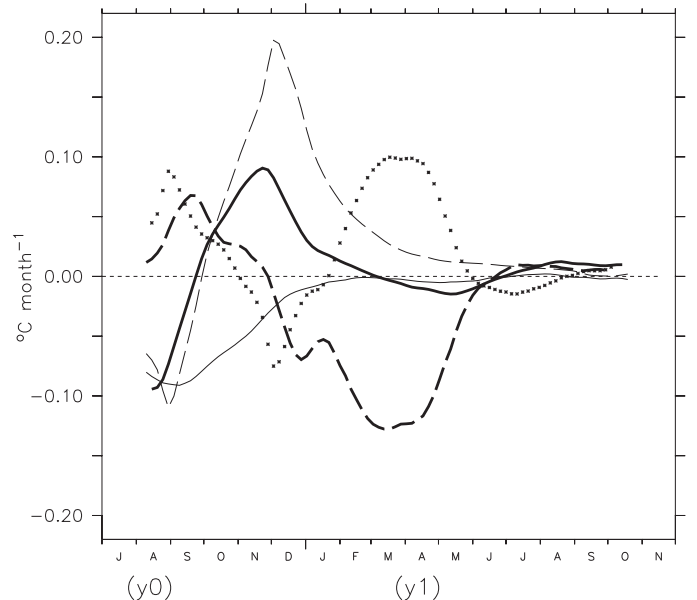

b) Northeast Pole (3x experiments)

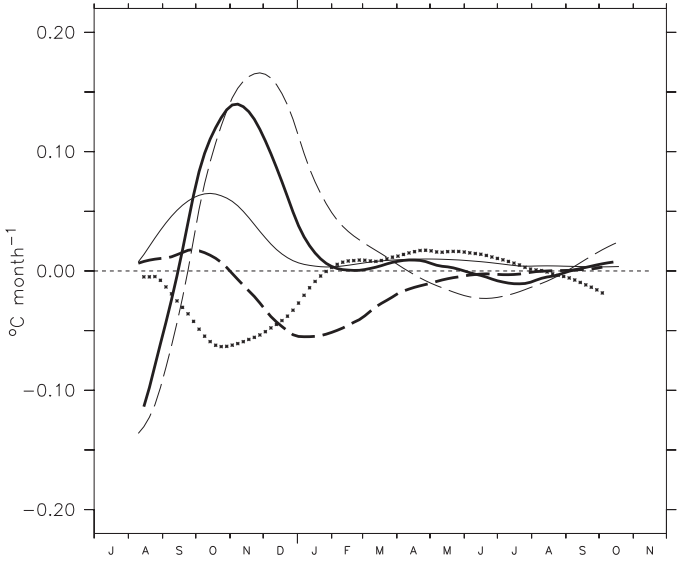

d) Northeast Pole ( $-3 x$ experiments)

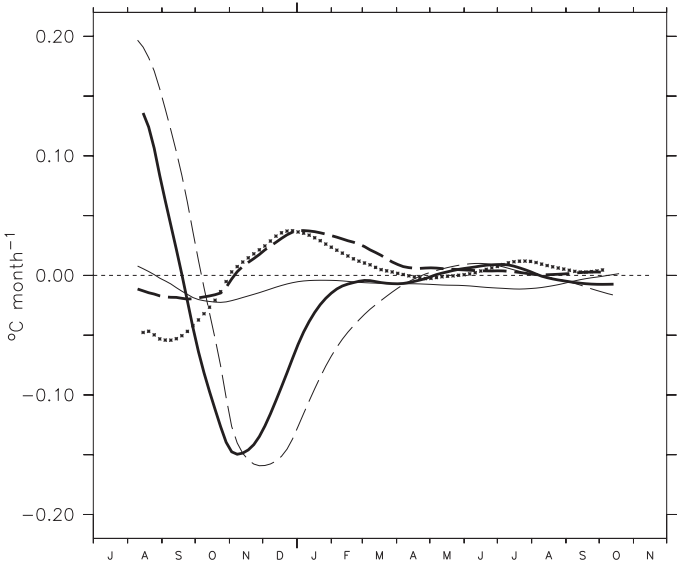

$(\mathrm{yO})$ northeast region (see Fig. S2). The southwest pole is shifted to $42^{\circ}-32^{\circ} \mathrm{S}, 17^{\circ}-1^{\circ} \mathrm{E}$, while the northeast pole is not modified. Both poles are set according to the original SASD spatial distribution rather than positioning them over specific areas where the memory effect is most intense. This choice comes from the focus given to the entrapment-entrainment mechanism. Each term from Eq. (1) is then calculated within the northeast and the new southwest poles.

\section{1) Northeast pole (ATMs)}

Figures $11 \mathrm{~b}$ and $11 \mathrm{~d}$ show that initial temperature anomalies, forced by anomalous wind applied between JJA(0), are mostly due to the contribution of surface NHF. After wind anomalies cease, those regions where mixed layer was warmed start to lose heat to atmosphere, while cooled areas start to gain heat. This adjustment in surface NHF peaks in late November(0), and fades until approximately May(1)-April(1). After the entrapment of temperature anomalies, which occurs near November(0), entrainment increases its contribution to $T_{m}$ until January(1), with the same signal as the SST anomaly in July(0), indicating that entrapped anomalies are feeding back to mixed layer temperature.

As also observed in OCN experiments (Fig. 6), most of the negative anomalies (Fig. 10) are concentrated south of the northeast pole. In both OCNs and ATMs, the initial temperature anomalies are consistent with a SASD pattern, for which the northeast pole is well positioned. However, the anomalies from memory effect are shifted southwestward of the original northeast pole, an indication of advection. In fact, in both cases, advection contributes with the opposite sign as the entrainment, indicating that the anomalies formed within northeast pole are advected out of that area (Figs. 7 and $11 b, d)$. 

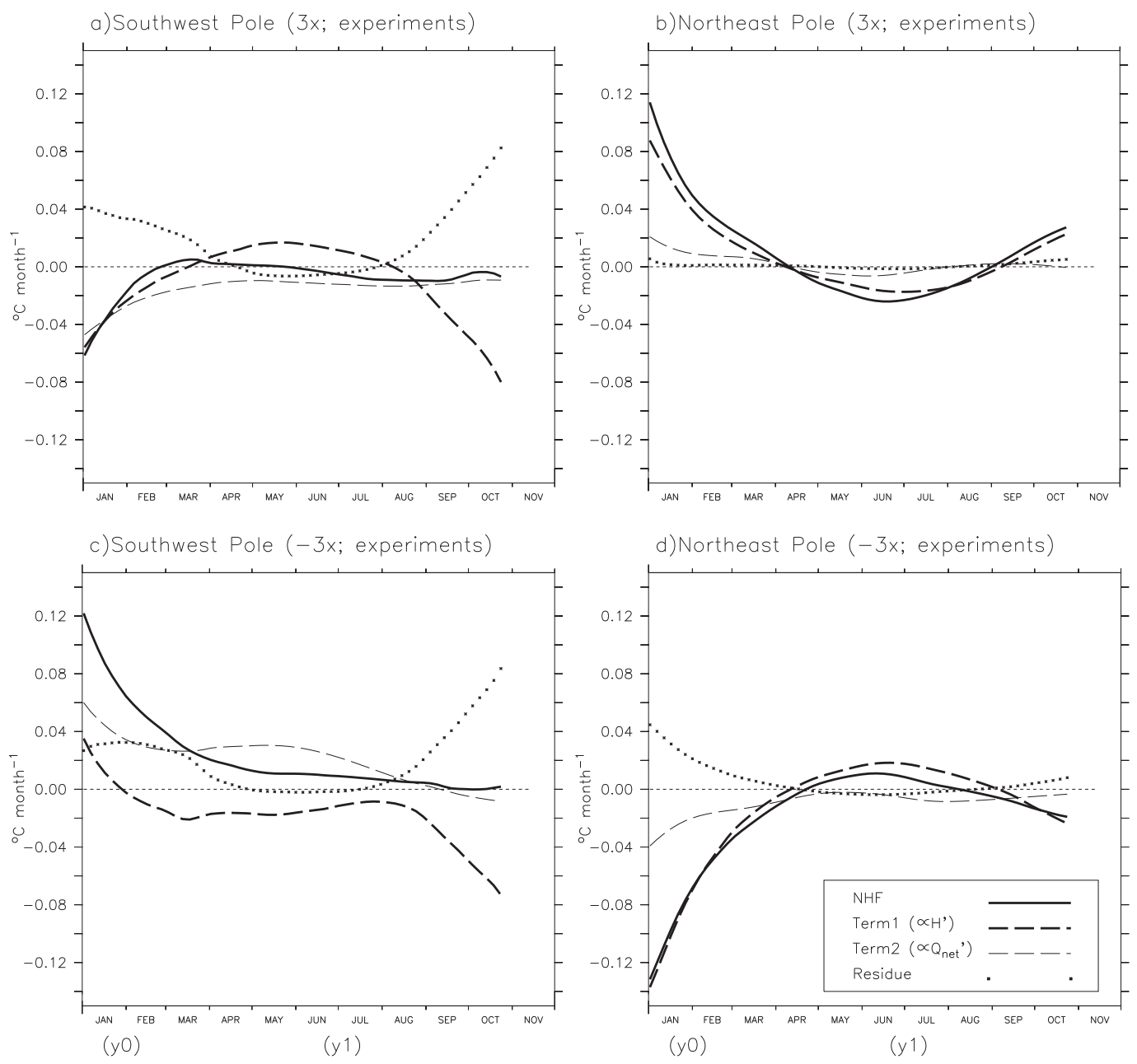

FIG. 12. The averaged anomalies of all terms in Eq. (4) $\left({ }^{\circ} \mathrm{C}\right.$ month $\left.^{-1}\right)$ for the ATM experiments (a),(b) $3 \times$ and (c),(d) $-3 \times$, averaged in the (a),(c) southwest and (b),(d) northeast poles.

The memory effect in this pole, which is represented in Figs. $11 \mathrm{~b}$ and $11 \mathrm{~d}$ by the returning of $T_{m}$ tendency to the same sign as in JJA(0), is observed near July(1). This peak is mostly due to surface NHF rather than to entrainment, as suggested from OCN experiments. After approximately March(1)-April(1), the sign of the contribution from surface NHF changes, becoming negative (positive) in $3 \times(-3 \times)$ experiments, contributing to decrease (increase) SST and restore SASD anomalies.

The expansion of the surface NHF contribution [Eq. (4)] reveals (Fig. 12) that the contribution from surface NHF to the memory effect is mostly due to anomalies of mixed layer thickness $\left(H^{\prime}\right)$, as observed in OCN experiments: the climatological heat loss to the atmosphere, between May(1) and August(1), has an enhanced (a weaker) effect in an anomalous thinner (thicker) mixed layer. In the $3 \times(-3 \times)$ experiments, the mixed layer becomes thinner (thicker) in the northeast pole (Fig. 10), which results in a negative (positive) contribution from $-\overline{Q_{\text {net }}} H^{\prime}$ to the SST anomaly in winter(1).

The expansion of the entrainment [Eq. (3)] shows that entrainment is highly controlled by anomalies in the vertical temperature gradient $\left(\Delta T^{\prime}\right)$, in both $3 \times$ and $-3 \times$ experiments (Figs. 13b,c). Hence, the memory effect in the northeast pole is a result of surface NHF overwhelming the contribution from entrainment, both toward the restoration of the original SST anomalies.

\section{2) SOuthwest POLE (ATMs)}

The southwest pole presents initial temperature anomalies in $\operatorname{JJA}(0)$ with a similar behavior to the northeast pole, with surface NHF leading the $T_{m}$ tendency, except that in the southwest region horizontal advection has also an important contribution. This contribution from the horizontal advection is also observed in the austral summer SASD events (MK11; Sterl 
a) Southwest Pole ( $3 x$ experiments)

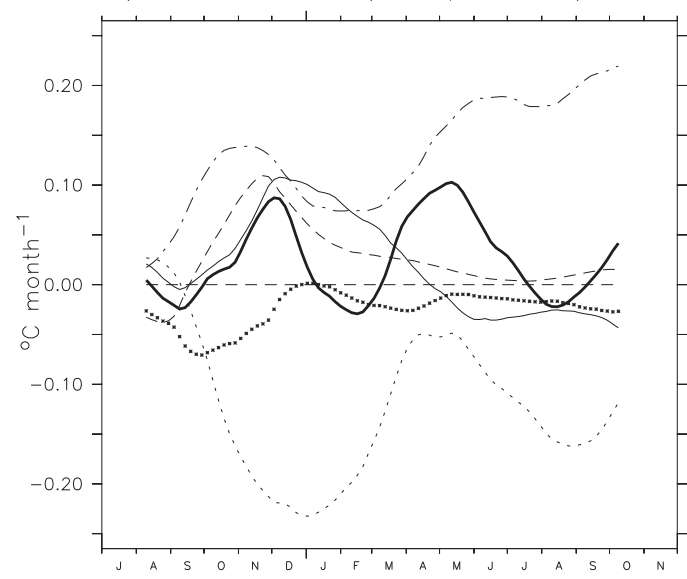

c) Southwest Pole ( $-3 \times$ experiments)

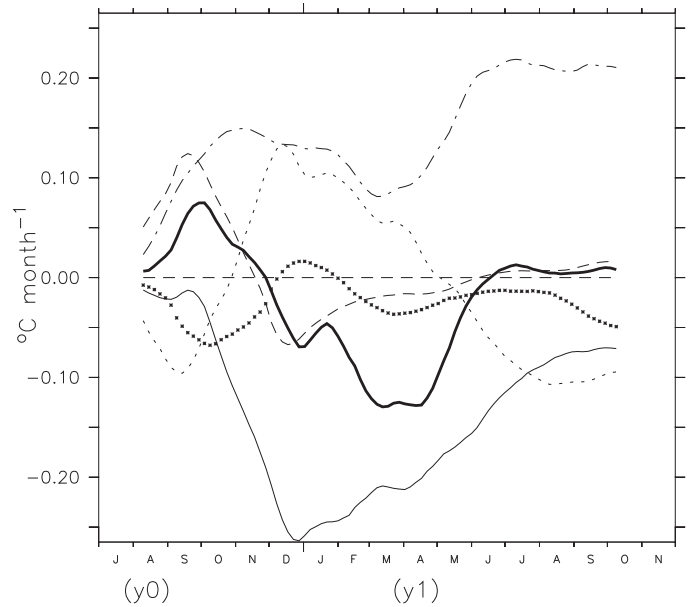

b) Northeast Pole (3x experiments)

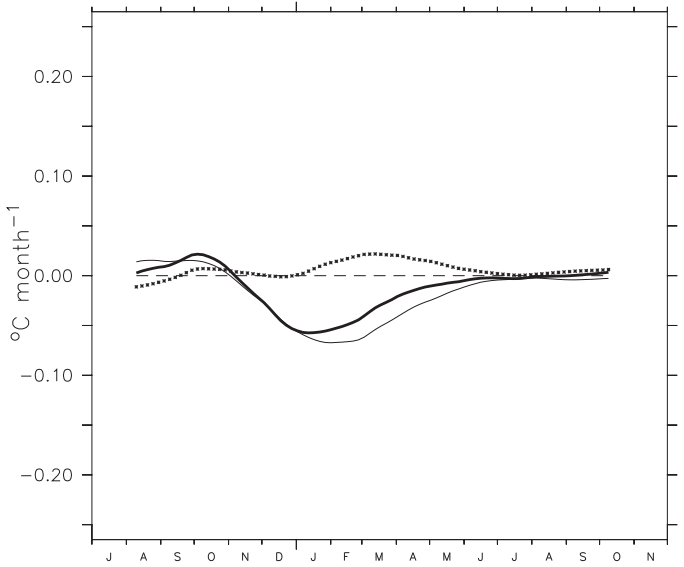

d) Northeast Pole ( $-3 x$ experiments)

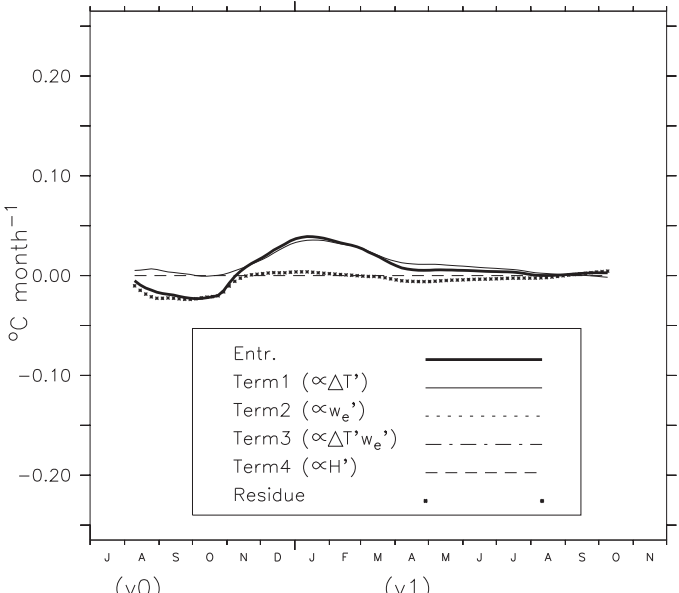

FIG. 13. The averaged anomalies from the terms in Eq. (3) $\left({ }^{\circ} \mathrm{C}\right.$ month $\left.^{-1}\right)$ for the ATM experiments (a),(b) $3 \times$ and (c),(d) $-3 \times$, averaged in the (a), (c) southwest and (b),(d) northeast SASD poles. In (b) and (d), terms 2, 3, and 4 of Eq. (3) (proportional to $\overline{\Delta T} w_{e}^{\prime}, w e^{\prime} \Delta T^{\prime}$, and $H^{\prime}$, respectively) are added to the residue.

and Hazeleger 2003), through anomalous geostrophic and Ekman transports.

The memory effect in the southwest pole, peaking in April(1)-May(1), is mostly forced by entrainment (Figs. 11a,c), with no direct contribution from surface NHF. The decomposition of surface NHF [Eq. (4)] shows that, in the southwest region (Figs. 12a,c), interactions between thickness anomaly and seasonal variability of surface NHF $\left(\propto-\overline{Q_{\text {net }}} H^{\prime}\right)$ also contribute toward the restoration of SASD anomalies; however, the contribution from $Q_{\text {net }}^{\prime}$ dominates surface NHF in the southwest region.

Decomposition of the entrainment term [Eq. (3)] shows that (Fig. 13), in both the $3 \times$ and $-3 \times$ experiments, temperature anomalies in the fossilized mixing region contribute to the memory effect, through $\Delta T^{\prime}$. However, especially in the $3 \times$ experiments, $w e^{\prime}$ becomes strong, increasing the contribution of the second $\left(\overline{\Delta T} w_{e}^{\prime}\right)$ and third ( $\left.w e^{\prime} \Delta T^{\prime}\right)$ terms in Eq. (3) to the $T_{m}$ tendency, as shown in Fig. 13. The increase in $w e^{\prime}$, which implies enhanced contributions of turbulent and nonlinear terms to entrainment, in ATMs is due to the experiment setup itself. All ATM experiments have started in June(0), six calendar months before OCN experiments, with anomalies in the wind forcing that introduce changes in the ocean circulation all over the domain. These anomalies evolve through the model integration, increasing the nonlinear anomalies especially in the more turbulent areas such as the southwest region, which encloses the South Atlantic Current. The increase in nonlinear terms is greater in $3 \times$ experiments, where the wind forcing in JJA(0) represents an intensification of the subtropical anticyclone, contributing to the asymmetry in this memory effect (Fig. 5). This shows 
that the increase in the turbulent anomalies, in the southwest area, acts to weaken or counterbalance the memory effect caused by the vertical temperature anomalies $\left(\Delta T^{\prime}\right)$.

\section{Summary and conclusions}

We have used several numerical experiments with an OGCM to investigate the effects that austral winterspring SASD events have in the South Atlantic. The idea behind this investigation was the possibility of interaction between a winter-spring SASD event and the formation of the fossilized mixing region. In the South Atlantic, the shallower summer mixed layer leaves below the water with winter-spring properties, until they mix again when the mixed layer starts to sink in next autumn. The hypothesis we have tested is that the fossilized mixing region might capture anomalies from a winter-spring SASD event, preserving them through summer, and then feed back on the SST in the next seasons.

Using a hindcast simulation, 10 austral summer SASD events were selected to be the subject of sensitivity tests. In the first set of experiments, the OCNs, temperature anomalies were directly prescribed within the fossilized mixing region, in November(0), right before those 10 austral summer SASD selected in the hindcast. It was found that, in the southwest SASD region, the entrapped anomalies consistently feed back to SST, in the direction of recovering the SASD anomalies that were in the fossilized mixing region. This memory effect acts, in the southwest region, from March(1) until July(1), producing a peak of SST anomalies in August(1), which fades until November(1).

In the second set of experiments, the ATMs, we have applied anomalies in the wind forcing, between June(0) and October(0), simulating the occurrence of a winterspring SASD event before the actual summer SASD selected in the hindcast simulation. We have found that both generation and entrapment of temperature anomalies have occurred in ATM experiments, resulting in a memory effect that restores SST anomalies from a winter spring SASD in the winter ocean conditions of the next year. However, the memory effect is weaker in ATMs, as well the induced temperature anomalies within the fossilized mixing region in these experiments, suggesting that the memory effect exists as long as the entrapment takes place efficiently.

Combining the heat budget analysis from both OCN and ATM experiments, the memory effect mechanisms are summarized as follows: In the northeast SASD region, SST anomalies, in winter(1), were formed by the combined contribution of entrainment and surface NHF. Entrainment was controlled directly by anomalies in the vertical temperature gradient $\left(\Delta T^{\prime}\right)$, which were created by entrapped temperature anomalies. Surface NHF contributes to the memory effect mostly by the combined effect of climatological ocean heat loss and anomalies of mixed layer thickness $\left(-\overline{Q_{\text {net }}} H^{\prime}\right)$ : the oceanic heat loss to atmosphere in winter has an enhanced (weaker) impact on SST in a thinner (thicker) mixed layer. In the southwest SASD region, on the other hand, anomalies of surface NHF were dictated by the term proportional to $Q_{\text {net }}^{\prime}$, preventing $-\overline{Q_{\text {net }}} H^{\prime}$ from directly contributing to the memory effect. Despite the prevalence of $Q_{\text {net }}^{\prime}$, the term $-\overline{Q_{\text {net }}} H^{\prime}$ acts to weaken the contribution from $Q_{\text {net }}^{\prime}$, allowing the entrainment to be effective in MAM(1).

Our results thus suggest that the mechanism that restores SST anomalies is different between both SASD poles. It was found that, in the northeast pole, the term $-\overline{Q_{\text {net }}} H^{\prime}$ overcomes $Q_{\text {net }}^{\prime}$, which made a direct contribution to surface NHF toward the memory effect. In the southwest region, on the other hand, $Q_{\text {net }}^{\prime}$ prevailed, and surface NHF did not contribute. Ekman pumping and turbulent and nonlinear contributions to entrainment were also different between SASD poles, contributing to weakening SST anomalies an enhancing its asymmetry. Differences of mixed layer annual cycle of each SASD region also contributed to their timing, through modulation of $\bar{H}$ and $\overline{w_{e}}$.

ATM experiments have also suggested that contributions from turbulent and nonlinear terms become more significant when anomalies were introduced in the wind forcing, which especially affects entrainment in the southwest region. This suggests that the memory effect might present a nonlinear response from a winter-spring SASD, since nonlinear anomalies might counterbalance the vertical temperature gradient contribution in most intense winter-spring SASD events.

Figure 14 summarizes the dominant terms that contribute to restore, in winter(1), the anomalies from a positive winter-spring(0) SASD event: SST anomalies peak first [April-June (AMJ)] in the southwest region (Fig. 14a), due to the contribution from vertical temperature anomalies $\left(\Delta T^{\prime}\right)$ to entrainment. Surface NHF is left out because it contributes only indirectly, with $-H^{\prime} \overline{Q_{\text {net }}}$ damping the negative contribution from $Q_{\text {net }}^{\prime}$. In the northeast region (Fig. 14b), both $-H^{\prime} \overline{Q_{\text {net }}}$ and $\Delta T^{\prime}$ act together to restore the SASD anomaly in JJA. The mechanism that restores anomalies from a negative winter-spring(0) SASD is the same as summarized in Fig. 14, but with opposite signs.

Morioka et al. (2011) have analyzed austral summer SASD events and suggested that, during its decay phase, anomalous entrainment is due only to anomalous temperature within the mixed layer. The memory effect 

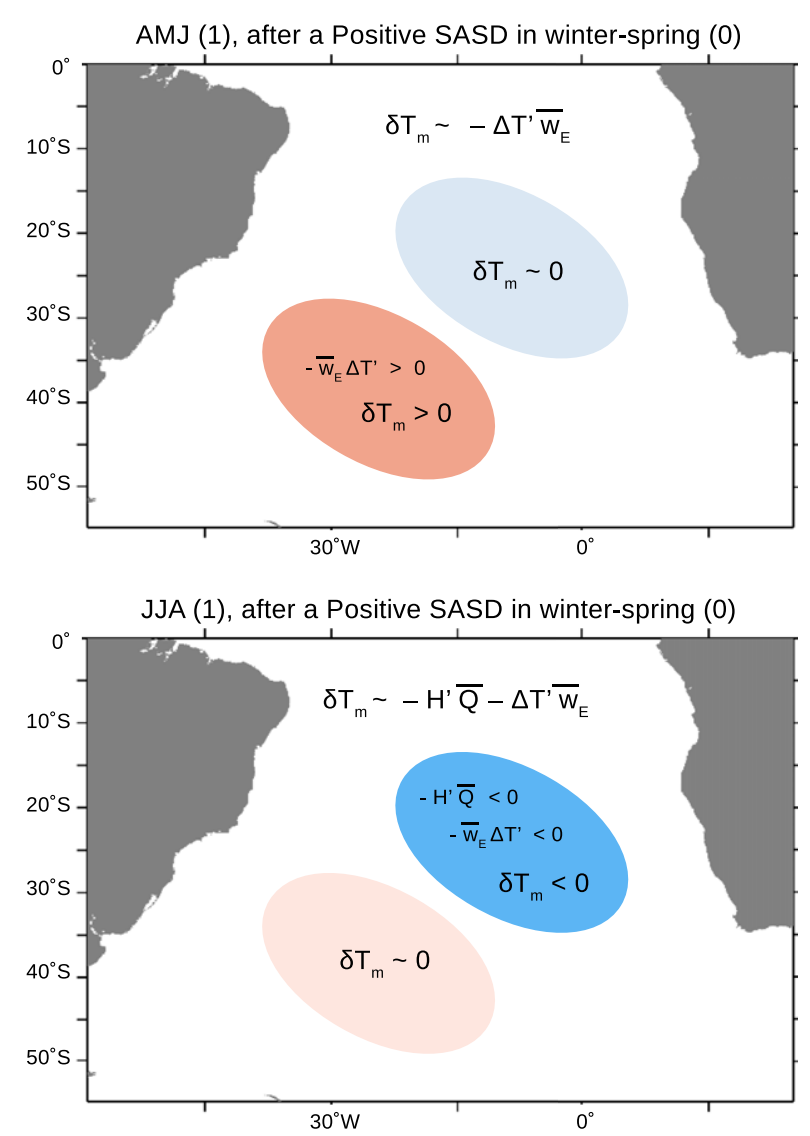

FIG. 14. Overall mechanisms that most contribute to the memory effect in both the southwest and northeast SASD poles.

suggests, on the other hand, especially from $\mathrm{OCN}$ experiments, that anomalous entrainment in early autumn is also produced by temperature anomalies below the mixed layer, affecting the decay phase of summer SASD events.

Compared to SST anomalies directly caused by SASD events, its memory effect recovered weaker and more scattered anomalies. It raises the question whether these anomalies would feed back to atmosphere and produce consistent responses. Answering this requires further investigation, with numerical simulations of AGCMs and coupled models. There are, however, previous studies that gave us insights in this matter. Bombardi et al. (2013) simulated the influence of SASD events on the SACZ during neutral ENSO, by prescribing SST anomalies. The authors have observed that SST anomalies shift meridionally the position of the SACZ-related cyclone, but in the opposite direction as observed by composing SASD events. This reflects the fact that SASD SST anomalies are forced by the atmospheric anomalous circulation, and not the other way around. However, fortunately, their experiments are a good approach to explore the influence of SST anomalies from the memory effect. Although the authors have investigated the austral summer, and the memory effect peaks in austral winter, their results suggest a possible impact from this memory effect on South Atlantic storm track. Haarsma et al. (2003) and Robertson et al. (2003) have also used SST anomalies from EOF/SVD analysis, related to SASD events, and found far-reaching atmospheric responses. They have used strong SST anomalies ( 3 or 4 times the standard deviation) to produce significant results; however, Bombardi et al. (2013) have found consistent atmospheric responses in the SACZ region from weak SST anomalies. There are, thus, good indications that this memory effect might impact the southwestern South American climate.

Regarding the connection between subtropical and tropical Atlantic, a possible link with the memory effect is not clear. Previous studies have suggested that Benguela Niño is connected with fluctuations in the St. Helena subtropical anticyclone in February-May, which evolves to an Atlantic Niño in austral winter (Lübbecke et al. 2010, 2014; Richter et al. 2010). Nnamchi et al. (2016) suggested that Atlantic Niño and austral winter SASD are so correlated that both may be parts of the same climate mode. However, the ability of SST anomalies, from the memory effect, peaking in JJA, to directly affect the subtropical anticyclone and Atlantic Niño is unclear. As mentioned, Haarsma et al. (2003) and Robertson et al. (2003) have performed experiments that are useful for this subject, but they have set their SST anomalies significantly stronger than those found here to obtain statistically significant results. There are, however, details in their experiment setup and model parameterization that can still be improved, so the memory effect feedback to atmosphere might still be significant. Haarsma et al. (2003), for example, have used a simplified GCM and time-invariant SST anomalies, which can be improved. Their results show no significant precipitation anomalies in the SACZ region, whereas other studies have suggested significant anomalies (Bombardi et al. 2013; Robertson et al. 2003). These uncertainties leave the question of whether SST anomalies, as those found here, might produce significant impacts on surrounding areas.

This study has suggested the existence of a memory effect using only OGCM simulations. Further investigations are required, preferably with ocean-atmosphere coupled models, to investigate whether these SST anomalies would feed back to the atmosphere and how far reaching this would be. The mixed layer anomalies due to the memory effect were also significant, and further investigations are required to explore whether those thickness anomalies impact ocean circulation. 
Acknowledgments. This paper was motivated by preliminary work conducted by E. Campos in collaboration with colleagues at NOAA's Atlantic Oceanographic and Meteorological Laboratory, in Miami, Florida. This research is part of Project SAMBAR, funded by the São Paulo State Foundation for Research Support (FAPESP, Grant 2017/09659-6). The first author is supported by a FAPESP postdoctoral fellowship (Grant 2017/25110-4) under the supervision of E. Campos. The numerical experiments were run with a model implemented during a previous project funded by FAPESP (SAMOC, Grant 2011/50552-4) with substantial contribution from P. Castellanos, supported by FAPESP postdoctoral scholarships under E. Campos supervision (Grants 2013/08572-3 and 2015/11366-1). During the final stages of the analyses E. Campos was working as a Research Fellow at the American University of Sharjah. E. Campos also acknowledges a Research Fellowship PQ-1A provided by the Brazilian Council of Scientific and Technological Development (CNPq, Grant 302018/2014-0). P. Castellanos has been supported by the project "COASTNET-Portuguese Coastal Monitoring Network (PINFRA/22128/2016)", funded by Foundation for Science and Technology (FCT).

Data availability statement. Data underlying our numerical experiments and finds are public. NOAA ERSST_V5 and NCEP-NCAR reanalysis data were provided by the NOAA/OAR/ESRL PSD, Boulder, Colorado, USA, from their website at https://www. esrl.noaa.gov/psd/.

\section{REFERENCES}

Anderson, T., and J. Finn, 1996: The New Statistical Analysis of Data. Springer-Verlag, $712 \mathrm{pp}$.

Ashok, K., S. K. Behera, S. A. Rao, H. Weng, and T. Yamagata, 2007: El Niño Modoki and its possible teleconnection. J. Geophys. Res., 112, C11007, https://doi.org/10.1029/2006JC003798.

Bleck, R., 2002: An oceanic general circulation model framed in hybrid isopycnic-Cartesian coordinates. Ocean Modell., 4, 5588, https://doi.org/10.1016/S1463-5003(01)00012-9.

Bombardi, R. J., L. M. V. Carvalho, and C. Jones, 2013: Simulating the influence of the South Atlantic dipole on the South Atlantic convergence zone during neutral ENSO. Theor. Appl. Climatol., 118, 251-269, https://doi.org/10.1007/s00704-013-1056-0.

$-, \ldots, \ldots$, and M. S. Reboita, 2014: Precipitation over eastern South America and the South Atlantic sea surface temperature during neutral ENSO periods. Climate Dyn., $\mathbf{4 2}$, 1553-1568, https://doi.org/10.1007/s00382-013-1832-7.

Carvalho, L. M. V., C. Jones, and B. Liebmann, 2002a: Extreme precipitation events in southeastern South America and largescale convective patterns in the South Atlantic convergence zone. J. Climate, 15, 2377-2394, https://doi.org/10.1175/15200442(2002)015<2377:EPEISS > 2.0.CO;2.

, — , and M. A. F. Silva Dias, 2002b: Intraseasonal large-scale circulations and mesoscale convective activity in tropical South America during the TRMM-LBA campaign. J. Geophys. Res., 107, 8042, https://doi.org/10.1029/2001JD000745.
Castellanos, P., E. Campos, I. Giddy, and W. Santis, 2016: Intercomparison studies between high-resolution HYCOM simulation and observational data: The South Atlantic and the Agulhas leakage system. J. Mar. Syst., 159, 76-88, https:// doi.org/10.1016/j.jmarsys.2016.02.010.

Chaves, R. R., and P. Nobre, 2004: Interactions between sea surface temperature over the South Atlantic Ocean and the South Atlantic convergence zone. Geophys. Res. Lett., 31, L03204, https://doi.org/10.1029/2003GL018647.

Chou, C., and J. D. Neelin, 2001: Mechanisms limiting the southward extent of the South American summer monsoon. Geophys. Res. Lett., 28, 2433-2436, https://doi.org/10.1029/2000GL012138.

Fauchereau, N., S. Trzaska, Y. Richard, P. Roucou, and P. Camberlin, 2003: Sea-surface temperature co-variability in the southern Atlantic and Indian Oceans and its connections with the atmospheric circulation in the Southern Hemisphere. Int. J. Climatol., 23, 663-677, https://doi.org/10.1002/joc.905.

Gill, A. E., 1980: Some simple solutions for heat-induced tropical circulations. Quart. J. Roy. Meteor. Soc., 106, 447-462, https:// doi.org/10.1002/qj.49710644905.

Haarsma, R. J., E. J. D. Campos, and F. Molteni, 2003: Atmospheric response to South Atlantic SST dipole. Geophys. Res. Lett., 30, 1864, https://doi.org/10.1029/2003GL017829.

,-- W. Hazeleger, C. Severijns, A. R. Piola, and F. Molteni, 2005: Dominant modes of variability in the South Atlantic: A study with a hierarchy of ocean-atmosphere models. J. Climate, 18, 1719-1735, https://doi.org/10.1175/JCLI3370.1.

Hermes, J. C., and C. J. C. Reason, 2005: Ocean model diagnosis of interannual coevolving SST variability in the South Indian and South Atlantic Oceans. J. Climate, 18, 2864-2882, https:// doi.org/10.1175/JCLI3422.1.

Huang, B., and Coauthors, 2017: Extended reconstructed sea surface temperature, version 5 (ERSSTv5): Upgrades, validations, and intercomparisons. J. Climate, 30, 8179-8205, https:// doi.org/10.1175/JCLI-D-16-0836.1.

Jerlov, N. G., 1951: Optical studies of ocean waters. Reports of the Swedish Deep-Sea Expedition, Vol. 3, 3-59.

Kalnay, E., and Coauthors, 1996: The NCEP/NCAR 40-Year Reanalysis Project. Bull. Amer. Meteor. Soc., 77, 437-471, https://doi.org/ 10.1175/1520-0477(1996)077<0437:TNYRP > 2.0.CO;2.

Kucharski, F., A. Bracco, J. H. Yoo, A. M. Tompkins, L. Feudale, P. Ruti, and A. Dell'Aquila, 2009: A Gill-Matsuno-type mechanism explains the tropical Atlantic influence on African and Indian monsoon rainfall. Quart. J. Roy. Meteor. Soc., 135, 569-579, https://doi.org/10.1002/qj.406.

Large, W. G., J. C. McWilliams, and S. C. Doney, 1994: Oceanic vertical mixing: A review and a model with a nonlocal boundary layer parameterization. Rev. Geophys., 32, 363-403, https://doi.org/10.1029/94RG01872.

Losada, T., B. Rodriguez-Fonseca, S. Janicot, S. Gervois, F. Chauvin, and P. Ruti, 2010: A multi-model approach to the Atlantic equatorial mode: Impact on the West African monsoon. Climate Dyn., 35, 29-43, https://doi.org/10.1007/s00382-009-0625-5.

Lübbecke, J. F., C. W. Böning, N. S. Keenlyside, and S.-P. Xie, 2010: On the connection between Benguela and equatorial Atlantic Niños and the role of the South Atlantic anticyclone. J. Geophys. Res., 115, C09015, https://doi.org/10.1029/2009JC005964.

_ N. J. Burls, C. J. C. Reason, and M. J. McPhaden, 2014: Variability in the South Atlantic anticyclone and the Atlantic Niño mode. J. Climate, 27, 8135-8150, https://doi.org/10.1175/JCLI-D-14-00202.1.

Matsuno, T., 1966: Quasi-geostrophic motions in the equatorial area. J. Meteor. Soc. Japan, 44, 25-43, https://doi.org/10.2151/ jmsj1965.44.1_25. 
Mo, K. C., and J. N. Paegle, 2001: The Pacific-South American modes and their downstream effects. Int. J. Climatol., 21, 1211-1229, https://doi.org/10.1002/joc.685.

Moisan, J. R., and P. P. Niiler, 1998: The seasonal heat budget of the North Pacific: Net heat flux and heat storage rates (19501990). J. Phys. Oceanogr., 28, 401-421, https://doi.org/10.1175/ 1520-0485(1998)028<0401:TSHBOT >2.0.CO;2.

Morioka, Y., T. Tozuka, and T. Yamagata, 2011: On the growth and decay of the subtropical dipole mode in the South Atlantic. J. Climate, 24, 5538-5554, https://doi.org/10.1175/ 2011JCLI4010.1.

— , S. Masson, P. Terray, C. Prodhomme, S. K. Behera, and Y. Masumoto, 2014: Role of tropical SST variability on the formation of subtropical dipoles. J. Climate, 27, 4486-4507, https://doi.org/10.1175/JCLI-D-13-00506.1.

Muza, M. N., L. M. V. Carvalho, C. Jones, and B. Liebmann, 2009: Intraseasonal and interannual variability of extreme dry and wet events over southeastern South America and the subtropical Atlantic during austral summer. J. Climate, 22, 1682 1699, https://doi.org/10.1175/2008JCLI2257.1.

Nicholson, S. E., and P. J. Webster, 2007: A physical basis for the interannual variability of rainfall in the Sahel. Quart. J. Roy. Meteor. Soc., 133, 2065-2084, https://doi.org/10.1002/qj.104.

Nnamchi, H. C., and J. Li, 2011: Influence of the South Atlantic Ocean dipole on West African summer precipitation. J. Climate, 24, 1184-1197, https://doi.org/10.1175/2010JCLI3668.1.

, and R. N. C. Anyadike, 2011: Does a dipole mode really exist in the South Atlantic Ocean? J. Geophys. Res., 116, D15104, https://doi.org/10.1029/2010JD015579.

, — - , F. Kucharski, I.-S. Kang, N. S. Keenlyside, P. Chang, and R. Farneti, 2016: An equatorial-extratropical dipole structure of the Atlantic Niño. J. Climate, 29, 7295-7311, https://doi.org/10.1175/JCLI-D-15-0894.1.

— F. Kucharski, N. S. Keenlyside, and R. Farneti, 2017: Analogous seasonal evolution of the South Atlantic SST dipole indices. Atmos. Sci. Lett., 18, 396-402, https://doi.org/10.1002/asl.781.

Polo, I., B. Rodríguez-Fonseca, T. Losada, and J. García-Serrano, 2008: Tropical Atlantic variability modes (1979-2002). Part I: Time-evolving SST modes related to West African rainfall. $J$ Climate, 21, 6457-6475, https://doi.org/10.1175/2008JCLI2607.1.

Qiu, B., and K. A. Kelly, 1993: Upper-ocean heat balance in the Kuroshio Extension region. J. Phys. Oceanogr., 23, 2027-2041, https://doi.org/10.1175/1520-0485(1993)023<2027: $\mathrm{UOHBIT}>2.0 . \mathrm{CO} ; 2$.

Richter, I., S. K. Behera, Y. Masumoto, B. Taguchi, N. Komori, and T. Yamagata, 2010: On the triggering of Benguela Niños: Remote equatorial versus local influences. Geophys. Res. Lett., 37, L20604, https://doi.org/10.1029/2010GL044461.

Robertson, A. W., and C. R. Mechoso, 2000: Interannual and interdecadal variability of the South Atlantic convergence zone.
Mon. Wea. Rev., 128, 2947-2957, https://doi.org/10.1175/15200493(2000)128<2947:IAIVOT>2.0.CO;2.

_ J. D. Farrara, and C. R. Mechoso, 2003: Simulations of the atmospheric response to South Atlantic sea surface temperature anomalies. J. Climate, 16, 2540-2551, https://doi.org/10.1175/15200442(2003)016\%3C2540:SOTART\%3E2.0.CO;2.

Rodrigues, R. R., E. J. D. Campos, and R. Haarsma, 2015: The impact of ENSO on the South Atlantic subtropical dipole mode. J. Climate, 28, 2691-2705, https://doi.org/10.1175/JCLI-D-14-00483.1.

Rouault, M., S. Illig, J. Lübbecke, and R. A. I. Koungue, 2018: Origin, development and demise of the 2010-2011 Benguela Niño. J. Mar. Syst., 188, 39-48, https://doi.org/10.1016/j.jmarsys.2017.07.007.

Smith, L. T., D. B. Boudra, and R. Bleck, 1990: A wind-driven isopycnic coordinate model of the north and equatorial Atlantic Ocean. 2. The Atlantic basin experiments. J. Geophys. Res., 95, 13 105-13128, https://doi.org/10.1029/JC095IC08P13105.

Sterl, A., and W. Hazeleger, 2003: Coupled variability and air-sea interaction in the South Atlantic Ocean. Climate Dyn., 21, 559-571, https://doi.org/10.1007/s00382-003-0348-y.

Taschetto, A. S., and I. Wainer, 2008: Reproducibility of South American precipitation due to subtropical South Atlantic SSTS. J. Climate, 21, 2835-2851, https://doi.org/10.1175/2007JCLI1865.1.

Thompson, D. W. J., J. M. Wallace, and G. C. Hegerl, 2000: Annular modes in the extratropical circulation. Part II: Trends. J. Climate, 13, 1018-1036, https://doi.org/10.1175/ 1520-0442(2000)013\%3C1018:AMITEC\%3E2.0.CO;2.

Tomczak, M., and J. S. Godfrey, 1995: Regional Oceanography: An Introduction. Wiley, $422 \mathrm{pp}$.

Trenberth, K. E., 1997: The definition of El Niño. Bull. Amer. Meteor. Soc., 78, 2771-2778, https://doi.org/10.1175/15200477(1997)078<2771:TDOENO > 2.0.CO;2.

Venegas, S. A., L. A. Mysak, and D. N. Straub, 1997: Atmosphereocean coupled variability in the South Atlantic. J. Climate, 10, 2904-2920, https://doi.org/10.1175/1520-0442(1997)010<2904: AOCVIT $>2.0 . \mathrm{CO} ; 2$.

Vizy, E. K., and K. H. Cook, 2001: Mechanisms by which Gulf of Guinea and eastern North Atlantic sea surface temperature anomalies can influence African rainfall. J. Climate, 14, 795821, https://doi.org/10.1175/1520-0442(2001)014\%3C0795: MBWGOG\%3E2.0.CO;2.

Wagner, R. G., and A. M. da Silva, 1994: Surface conditions associated with anomalous rainfall in the Guinea coastal region. Int. J. Climatol., 14, 179-199, https://doi.org/10.1002/joc.3370140205.

Ward, M. N., 1998: Diagnosis and short-lead time prediction of summer rainfall in tropical North Africa at interannual and multidecadal timescales. J. Climate, 11, 3167-3191, https://doi.org/10.1175/ 1520-0442(1998)011\%3C3167:DASLTP\%3E2.0.CO;2.

Zhou, J., and K.-M. Lau, 1998: Does a monsoon climate exist over South America? J. Climate, 11, 1020-1040, https://doi.org/ 10.1175/1520-0442(1998)011<1020:DAMCEO>2.0.CO;2. 